\title{
MÉTODOS Y ANÁLISIS PARA LA CARACTERIZACIÓN DE CERÁMICAS ARQUEOLÓGICAS. ESTADO ACTUAL DE LA INVESTIGACIÓN EN ESPAÑA
}

\author{
POR \\ MANUEL GARCÍA HERAS \\ Universidad Complutense de Madrid \\ $\mathrm{Y}$ \\ CARLOS OLAETXEA \\ Sociedad de Ciencias Aranzadi, San Sebastián
}

\begin{abstract}
RESUMEN
En este trabajo mostramos cuál puede ser el potencial de estudio y algunas de las limitaciones que tienen los métodos más comúnmente empleados en los análisis de caracterización de cerámicas arqueológicas. Tras realizar un repaso por la bibliografía que se ha producido hasta el momento en nuestro país sobre este tema, comprobamos que este tipo de técnicas todavía no se ha desarrollado en toda su amplitud, siendo necesaria su integración en el marco de aproximaciones más rigurosas que contemplen el fenómeno de la cerámica como un factor más de los que interactúan en el seno de las comunidades del pasado.
\end{abstract}

\section{SUMMARY}

In this paper we show the potential study and some limitations of the foremost analytical methods used in the characterization of archaeological ceramics. A general review of the literature carried out on the application of this kind of techniques within the spanish research, has shown us the need of developing more rigorous archaeologically oriented approaches in order to consider pottery as a topic interrelated with all the other elements within the past communities. 
Durante los últimos veinte años hemos asistido a un creciente desarrollo en el uso de métodos científicos aplicados a los objetivos de la investigación arqueológica. Dentro de estos métodos han adquirido un interés notable las técnicas de análisis de objetos arqueológicos y en particular las referentes al estudio de cerámicas. En nuestro país, como ha ocurrido en otros aspectos de la investigación científica, este desarrollo no ha ido parejo al avance que se ha producido en otros países con respecto a los análisis efectuados sobre los materiales de excavación. Mientras que en algunos de ellos esta práctica viene siendo habitual desde hace ya algún tiempo, en España todavía no se aplica de forma generalizada y son pocos los estudios que se han llevado a cabo. Por esta razón, creemos importante hacer una llamada de atención hacia este tipo de técnicas de análisis y mostrar cuál puede ser su potencial en la resolución de problemas arqueológicos. Estos planteamientos nos han llevado a realizar una reflexión crítica de la bibliografía que hasta el momento se ha producido en nuestro país sobre este tema y a elaborar un apéndice final en el que veremos cuáles son los métodos con los que contamos en la actualidad para la caracterización de materiales cerámicos, cuáles son sus ventajas y limitaciones, cuál es su grado de resolución y qué tipo de cuestiones pueden resolver.

\section{INTRODUCCIÓN}

La caracterización de cerámicas arqueológicas se incluye dentro de lo que se ha denominado Arqueometría. El término "Arqueometría» se empezó a utilizar en la investigación arqueológica a raíz de la publicación del primer número de la revista inglesa Archaeometry en 1958 por el Oxford Research Laboratory of Archaeology and the History of Art. El término hace referencia al conjunto de técnicas físico-químicas que se emplean para la resolución de problemas arqueológicos. La Arqueometría se aplica en tres campos básicos de estudio: 1) La localización de sitios arqueológicos por medios geofísicos de prospección. 2) La datación absoluta o cronométrica. 3) La caracterización y procedencia de materiales (Butzer, 1989: 153).

Queda claro pues, que la caracterización es uno de los campos de estudio de la Arqueometría, concretamente el que se refiere a las técnicas físico-químicas de examen de objetos arqueológicos que se utilizan con el fin de identificar las propiedades características del material o los materiales que los constituyen. En algunos casos estas técnicas pueden determinar el origen de los mismos. Su aplicación en arqueología descansa sobre la asunción de que la cerámica es un recurso de información arqueológica con relaciones específicas, repetidas y definibles, entre las materias primas que la componen y los productos acabados derivados de ellas (cerámica). De esta forma, resulta razonable suponer que en el pasado la pasta cerámica formó parte de la tradición alfarera igual que la forma y la decoración (Buko, 1984; Peacock, 1970). Partiendo de este razonamiento, es importante resaltar que cualquier aproximación que intente abordar en su conjunto el fenómeno de la cerámica arqueológica deberá tener en cuenta la interacción entre estos tres factores: pasta, o lo que es lo mismo, su materia prima, forma y decoración.

Las técnicas de caracterización de cerámicas arqueológicas comenzaron a utilizarse por norteamericanos e ingleses en la década de los 50 tras comprobar que había problemas, como la cuestión de los orígenes y procedencia de los materiales cerámicos prehistóricos o los procesos de su manufacturación, que no podían resolverse desde planteamientos puramente arqueológicos sin la ayuda y apoyo de otras disciplinas (Sayre y Dodson, 1957). Estos países cuentan con 
un gran desarrollo en la actualidad en estas técnicas al tener una experiencia detrás de casi ya treinta años. En los años 70 otra serie de países como Francia, Suiza, Alemania o Suecia, comenzaron también a aplicar en sus programas de investigación toda esta analítica. En nuestro país, salvo algún trabajo aislado que luego tendremos oportunidad de comentar, ha sido solamente a partir de los años 80 cuando ha empezado a utilizarse. Es lógico, por tanto, observar como en las aproximaciones españolas existentes se echa en falta cierta sistematización y apoyo metodológico. No podemos olvidar que en estos países hay toda una tradición que respalda este tipo de aproximaciones precisamente por la larga experiencia que tienen a sus espaldas. Una prueba de ello es la publicación periódica de revistas especializadas en la materia, como la mencionada Archaeometry, el Journal of Archaeological Science o la más reciente Révue d'Archéometrie francesa, además de la aparición de trabajos colectivos que tratan de reflexionar sobre los avances que se están produciendo (Hughes, 1981; Freestone et al., 1982; Slater y Tate, 1988; Middleton y Freestone, 1991).

Con estas técnicas se han tratado de resolver dos tipos de cuestiones dentro de los estudios cerámicos. Por un lado, las relacionadas con la naturaleza de las arcillas, que tienen como fin principal incidir en cuestiones tecnológicas. Por otro, aquellas que se refieren a la procedencia de las materias primas con las que se ha elaborado la cerámica. No es necesario insistir en que ambos aspectos deberían complementarse, aunque sin embargo, son muchas las aproximaciones que sólo muestran interés por uno de ellos.

La tradición arqueológica anglosajona, muy relacionada con los estudios antropológicos y muy interesada en valorar en sus interpretaciones los aspectos del comportamiento social, se interesó desde el principio en la reconstrucción de los patrones de comercio e intercambio de las sociedades del pasado a través de la caracterización de sus materiales cerámicos, sus pautas de distribución, la información etnográfica y la experimentación con los tipos de manufactura observada. No en vano Renfrew, en un trabajo de 1977, señalaba que había dos tipos de aproximaciones dentro de los estudios de comercio e intercambio. Una teórica, relacionada con la antropología económica, y una pragmática, que se desarrollaba con la aplicación de las nuevas técnicas analíticas a los materiales de excavación (Renfrew, 1977). Aunque en las aproximaciones anglosajonas no podemos decir que se descuiden los aspectos tecnológicos, sí podemos afirmar que el mayor peso específico recae sobre la distribución de artefactos caracterizados. Un ejemplo de esto lo podemos ver en el recientemente publicado manual de arqueología de Renfrew y Bahn (1991: 314-320), donde la caracterización de materiales arqueológicos es tratada en el capítulo dedicado a comercio e intercambio.

Como resultado de la gran influencia que ha ejercido sobre este tipo de estudios el inmenso volumen de publicaciones anglosajonas sobre el tema, en la actualidad hacer referencia a un estudio sobre caracterización es casi sinónimo de análisis de procedencia de las materias primas y reconstrucción de los patrones de producción, intercambio y comercio.

Dado que con la caracterización se intenta poner en relación los materiales que conforman una cerámica con el entorno geológico en donde ésta se ha hallado para poder determinar su origen, es impotante contar con un buen conocimiento geológico de la distribución de las materias primas que pudieron utilizarse en su manufactura. Por ello, disponer de una buena cartografía geológica y de buenos trabajos regionales es del todo indispensable. Algunos autores recomiendan incluso, siempre que sea viable, la recogida sistemática de muestras actuales de arcilla potencialmente utilizables del área de estudio con el fin de poder contrastar los resultados de 
la caracterización (Wilson, 1978; Echallier, 1984). Si a todo ello unimos el poder manejar cerámicas bien contextualizadas, Ilegaremos a la conclusión de que este tipo de técnicas pueden ofrecernos datos de gran interés sobre aspectos tecnológicos, sociales, económicos y culturales que pueden sernos de mucha utilidad para emprender reconstrucciones más precisas acerca de las comunidades del pasado.

\section{LOS TRABAJOS DE CARACTERIZACIÓN DE CERÁMICAS EN ESPAÑA}

Como hemos señalado al principio de estas líneas, los estudios de caracterización de cerámicas se han ido introduciendo de una manera lenta en la investigación española y han tenido un desarrollo tardío con respecto a otros países. Tenemos que esperar hasta la década de los 70 para encontrar los primeros trabajos (Antón et al., 1972; Antón, 1973; Aranegui y Antón, 1973; Galván et al., 1973; Díaz Balde, 1975) en los que se trata de analizar un reducido número de muestras de yacimientos concretos poniendo en práctica dos o tres técnicas entre las que se encuentra siempre la Difracción de Rayos X. Generalmente sólo se intenta conocer la composición mineralógica de las cerámicas y su tecnología. Hasta finales de esta década no nos encontramos con trabajos que intenten resolver problemas relacionados con la procedencia de las materias primas utilizadas en su elaboración, aunque en este primer momento todavía son tímidos intentos carentes de una estrategia global de investigación (Gallart, 1977; Capel y Delgado, 1978; Capel et al., 1979).

Sin embargo, es sólo a partir de los años 80 cuando este tipo de técnicas empieza a irrumpir en la bibliografía española (vid. fig. 2). Es ahora cuando comienzan a utilizarse otras técnicas de análisis intentando conjugar los resultados de cada una de ellas. Una de las primeras aportaciones es la de Gracia (1980), la cual analiza cerámica ibérica y griega con métodos que se utilizan por vez primera en nuestro país, como la Espectroscopía Mössbauer o la Espectrometría de Absorción Atómica. También hay trabajos que introducen otros métodos, como los de Peláez (1982-83) y González y Pina (1983) basados en el análisis petrográfico sobre lámina delgada, o gran parte de los que ha llevado a cabo Rincón (1981 a y b; 1983; 1985 a, b, c y d; 1986; Rincón y Valle, 1983), en los que destaca la utilización de microsondas electrónicas para conocer la composición de microestructuras en algunos elementos superficiales de las cerámicas. Por otro lado, continúa habiendo estudios que siguen la tónica ya comentada para los trabajos realizados en la década anterior (Padilla, 1980; Galván, 1980-81; Martín Patino, 1985; Barba, 1986; Ayala y Ortiz, 1987, 1989; Galván y Galván, 1987, 1988; Gallart y López, 1988 a; Isidro y Navarro, 1990).

Junto a los trabajos realizados específicamente con cerámicas arqueológicas, hay que mencionar algunos otros que también tienen incidencia, aunque no de forma directa, con los estudios de caracterización. En este sentido son importantes algunas aportaciones que a pesar de no haberse realizado desde planteamientos puramente arqueológicos pueden resultar de gran ayuda a la hora de caracterizar las cerámicas de una región determinada. Nos referimos a aquellos trabajos que estudian la arcilla desde el punto de vista de su aprovechamiento industrial ${ }^{\text {, }}$, aque-

1 Para una completa información sobre los trabajos efectuados en cada región española puede consultarse el Boletín de la Sociedad Española de Cerámica y Vidrio. 
llos otros que han mostrado interés en el análisis de las materias primas utilizadas en la alfarería popular actual (p. e. García Ramos, et al., 1974), o los que se han centrado en estudiar las propiedades físico-químicas de las arcillas que componen una cerámica y su comportamiento a lo largo de la cocción (entre otros González Peña, 1974: Linares et al., 1983).

Si centramos nuestra atención en los diferentes estudios que se han producido dentro de cada uno de los períodos históricos en los que interviene la investigación arqueológica ${ }^{2}$, podemos ver que una de las etapas que mayor interés ha recibido en los análisis sobre caracterización de cerámicas en nuestro país ha sido el Neolítico. Principalmente gracias a la labor desarrollada por uno de los primeros equipos interdisciplinares que con carácter permanente funciona en España desde finales de los 70. Este equipo se formó debido a la colaboración existente entre el Departamento de Prehistoria de la Universidad de Granada y la Sección de Físico-Química y Geoquímica Mineral de la Estación Experimental del Zaidín (C.S.I.C.) de esta misma ciudad. Sus trabajos se han centrado en el estudio de la cerámica neolítica de esta provincia (Capel et al.. 1982, 1986 a y b) haciendo especial hincapié en la cerámica «a la almagra» (Navarrete y Capel, 1980; Capel et al., 1983; 1984). Junto a estos trabajos también son de gran interés los que ha realizado M. D. Gallart con materiales neolíticos valencianos (Gallart, 1980 a y b) y con materiales de la cueva de Chaves (Gallart y López, 1988 b). La creación del Laboratorio de Termoluminiscencia y Analítica de Cerámicas de la Universidad Autónoma de Madrid ${ }^{3}$ a finales de los años 80 , también ha supuesto algunas aproximaciones importantes al fenómeno de la cerámica neolítica (Arribas et al., 1988-89) aunque han realizado igualmente análisis sobre otros tipos de cerámica (Arribas et al., 1987; 1991; Millán et al., 1991).

Este buen número de trabajos realizados sobre cerámica neolítica contrasta por otro lado con la escasez que presenta este tipo de analítica en estudios de cerámica de otros períodos. En etapas como el Calcolítico apenas se ha iniciado el análisis de sus cerámicas (Ayala y Ortiz, 1987, 1989). En la Edad del Bronce a pesar de que existen ya varios trabajos en sus diferentes períodos cronológicos ${ }^{4}$, todavía no constituyen una iniciativa establecida. Igual suerte han corrido los estudios efectuados con materiales de la Edad del Hierro, en donde si exceptuamos los que se han llevado a cabo con cerámica ibérica ${ }^{5}$ los trabajos han sido escasos.

Resulta importante resaltar cómo en la arqueología clásica y medieval, períodos en los cuales existe una rica y variada evidencia directa de su producción cerámica a través de restos de hornos y talleres, todavía no se ha iniciado de una forma generalizada la caracterización de sus producciones. Por contra, los trabajos más importantes que se han realizado en esta dirección

2 No podemos olvidar aquí algunas de las aportaciones que han tenido lugar en el estudio de materiales cerámicos americanos, entre las cuales destacan los trabajos de Galván et al. (1974, 1989), Guinea y Galván (1976) y Mingarro y López (1982).

${ }^{3}$ La información sobre el acceso a los servicios que presta este laboratorio se ofrece en Calderón et al. (1988).

4 Trabajos realizados por Galván et al. (1973), Gallart (1977), Capel y Delgado (1978), Capel et al. (1979, 1985), Galván (1980-81), Rincón y Valle (1983), González et al. (1983, 1985 a y b, 1988), Rincón (1985 a y c), Martín Socas et al. (1985, 1989), Capel (1986), Galván y Galván (1987), Gallart y López (1988 a), Arribas et al. (1988-89), Rincón y Alonso (1990), Millán et. al. (1991) y Barrios et al. (1991 a).

5 Realizados por Antón et al. (1972), Antón (1973), Aranegui y Antón (1973), Peláez (1982-83), González et al. (1983, 1985 a y b, 1988), Rincón (1985 b), Gancedo et al. (1985), Castelo y Rincón (1986, 1987), Galván y Galván (1987) y Muñoz et al. (1991). 
han sido efectuados por autores extranjeros, principalmente franceses, destacando los trabajos de Picon (1984) y Tavares (1984) sobre los centros de producción de sigillata hispánica y los realizados con cerámicas medievales hispanomusulmanas por Bazzana et al. (1986), Demians et al. (1986) y Picón y Navarro (1986). Esta situación trata de paliarse en la actualidad en lo referente a producciones cerámicas romanas gracias a la existencia del proyecto OFFICINA, que tiene entre sus objetivos documentar los restos de hornos y talleres en la Península Ibérica y a través de la aplicación de nuevas metodologías, entre las que se encuentra la caracterización de sus producciones, emprender su estudio en función del papel económico que jugaron (Juan Tovar, 1992; Juan Tovar y Bermúdez, 1991).

Por lo demás, los estudios de caracterización de cerámicas en estos períodos son bastante escasos. Pocos son los realizados por ejemplo con cerámica romana (Rincón, 1985 b, 1986; Barba, 1986; González et al., 1983, 1985 a y b, 1988; Galván y Galván, 1988; Vendrell-Saz et al., 1991; Aguarod, 1991; Muñoz et al., 1991) en los que producciones tan importantes desde el punto de vista comercial como la terra sigillata o las ánforas ${ }^{6}$ todavía no han sido estudiadas con esta metodología si exceptuamos el trabajo de Rincón (1985 d). El caso de la cerámica medieval es muy similar, aunque es notable el avance que se ha producido en el estudio de las cerámicas grises catalanas gracias a la existencia de un equipo interdisciplinar en la Universidad de Barcelona que trabaja en un proyecto conjunto de Arqueometría desde el año 1984 (Riu, 1986; Pradell et al., 1991; Aliaga et al., 1991). En cualquier caso, hay pocos trabajos que hayan tratado de caracterizar la producción de alfares conocidos (Aguado, 1986; Aguado et al., 1990); Martín Patino, 1985) y son igualmente escasos los que se han dedicado al análisis de cerámicas medievales en general (Padilla, 1980; Gerrard y Gutiérrez, 1988, 1991; Urteaga, 1991).

A pesar de la existencia del grupo interdisciplinar de Granada y del Laboratorio de la Universidad Autónoma de Madrid mencionados anteriormente, o del grupo de la Universidad de Barcelona, no podemos decir que los análisis sobre caracterización de cerámicas constituyan por el momento un campo de estudio contínuo y establecido dentro de la investigación arqueológica española como demuestra la figura 2 . Un buen ejemplo de ello lo podemos observar en la falta de aproximaciones que tengan en cuenta entre sus objetivos la toma de muestras actuales de arcilla como medio de contrastar los resultados, aunque hay notables excepciones (Capel, 1986; Martín Socas et al., 1985; Barrios et al., 1991 b), o la falta de una planificación en los análisis siguiendo una estrategia regional. Por otro lado, tampoco es frecuente en nuestras publicaciones explicitar cuáles son las cuestiones arqueológicas que se pretenden resolver con los métodos de análisis utilizados, si exceptuamos las relacionadas con la composición mineralógica y los aspectos tecnológicos. De los 65 trabajos que nos han servido para confeccionar los gráficos de las figuras 1 y 2, sólo en un número muy reducido (Gallart, 1980 a; Capel, 1986) se intenta trascender los resultados analíticos y conectarlos con una interpretación arqueológica más global. De este modo, estudios como el que ha llevado recientemente a la práctica el grupo de Granada (Navarrete et al., 1991) culminando todo un proceso de trabajo realizado sobre las cerámicas neolíticas granadinas a lo largo de casi diez años, constituyen toda una excepción en nuestra investigación. Si echamos un vistazo al gráfico de la figura 1 que muestra cuáles han

${ }^{6}$ Esta situación contrasta por ejemplo con la que presenta el estudio de las ánforas lusitanas, en las cuales ya se han emprendido recientemente estudios de caracterización (Tavares, 1990; Pinto y Cardoso, 1990). 
sido los métodos que se han utilizado en los diferentes trabajos sobre caracterización, podemos comprobar que se han empleado más aquellos que podían estar a un mayor alcance de los arqueólogos en detrimento de otros cuyo coste o grado de complejidad les alejaban de su utilización. Por ello, ciertos tipos de análisis como el de Activación Neutrónica, han sido escasamente desarrollados. Nosotros solamente tenemos constancia del llevado a cabo con materiales del yacimiento sevillano de Cerro Macareno (González et al., 1983; 1985 a y b).

El escaso desarrollo de estas técnicas analíticas también ha quedado reflejado fuera de nuestras fronteras. Si examinamos con detenimiento algunas de las publicaciones internacionales es-

Porcentajes

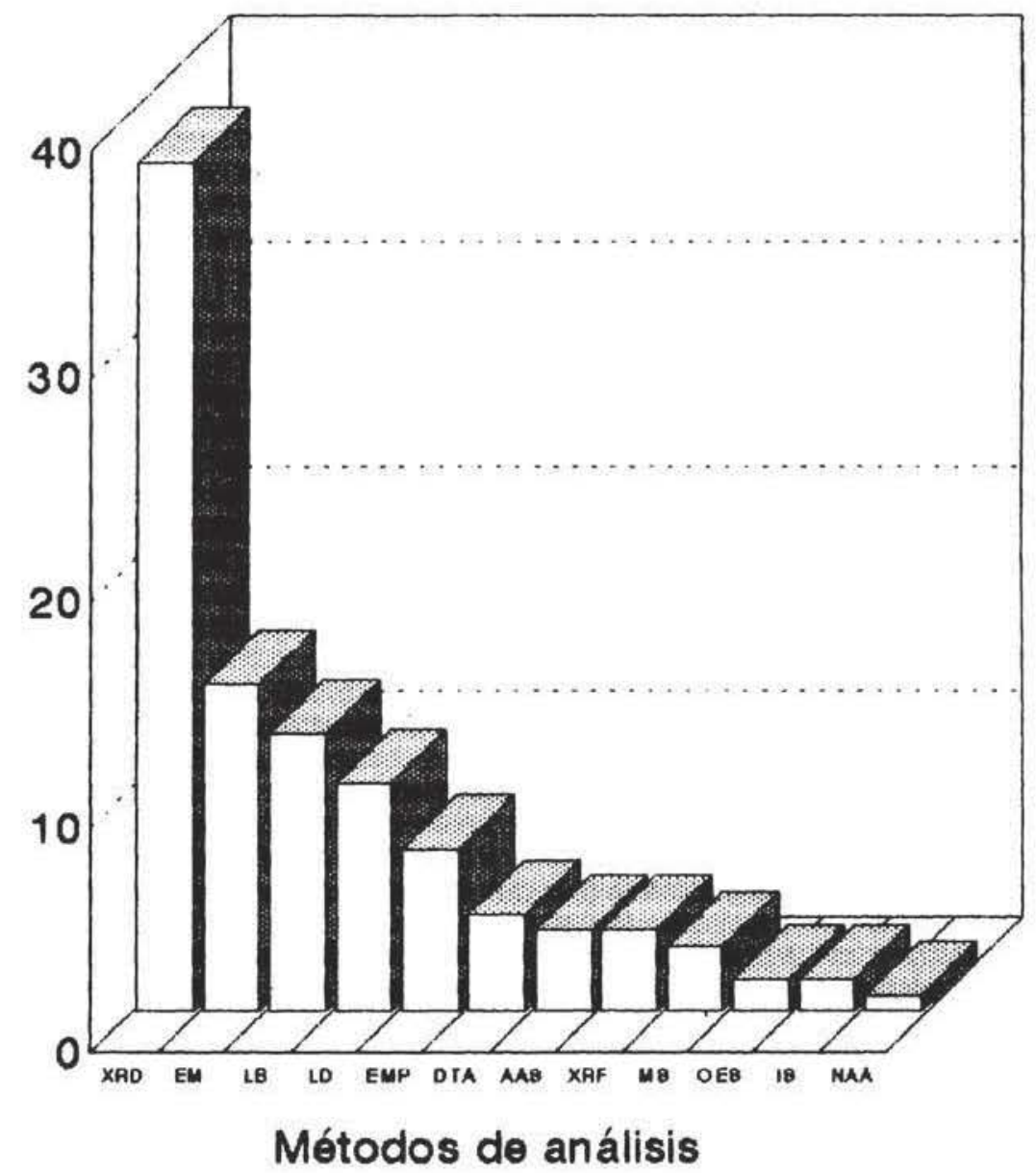

Fig. 1. Métodos de análisis empleados en las publicaciones españolas (Período 1972-1991). N. ${ }^{\circ}$ trabajos: 65 .

Métodos: XRD: Difracción Rayox X; EM: Microscopía Electrónica; LB: Lupa Binocular; LD: Lámina Delgada; EMP: Sonda Electrones; DTA: Análisis Térmico Diferencial; AAS: Espectrometría Absorción Atómica; XRF: Fluorescencia Rayox X; MS: Espectroscopía Mössbauer; OES: Espectrometría Emisión Óptica; IS: Espectroscopía Infrarrojos; NAA: Activación Neutrónica. 


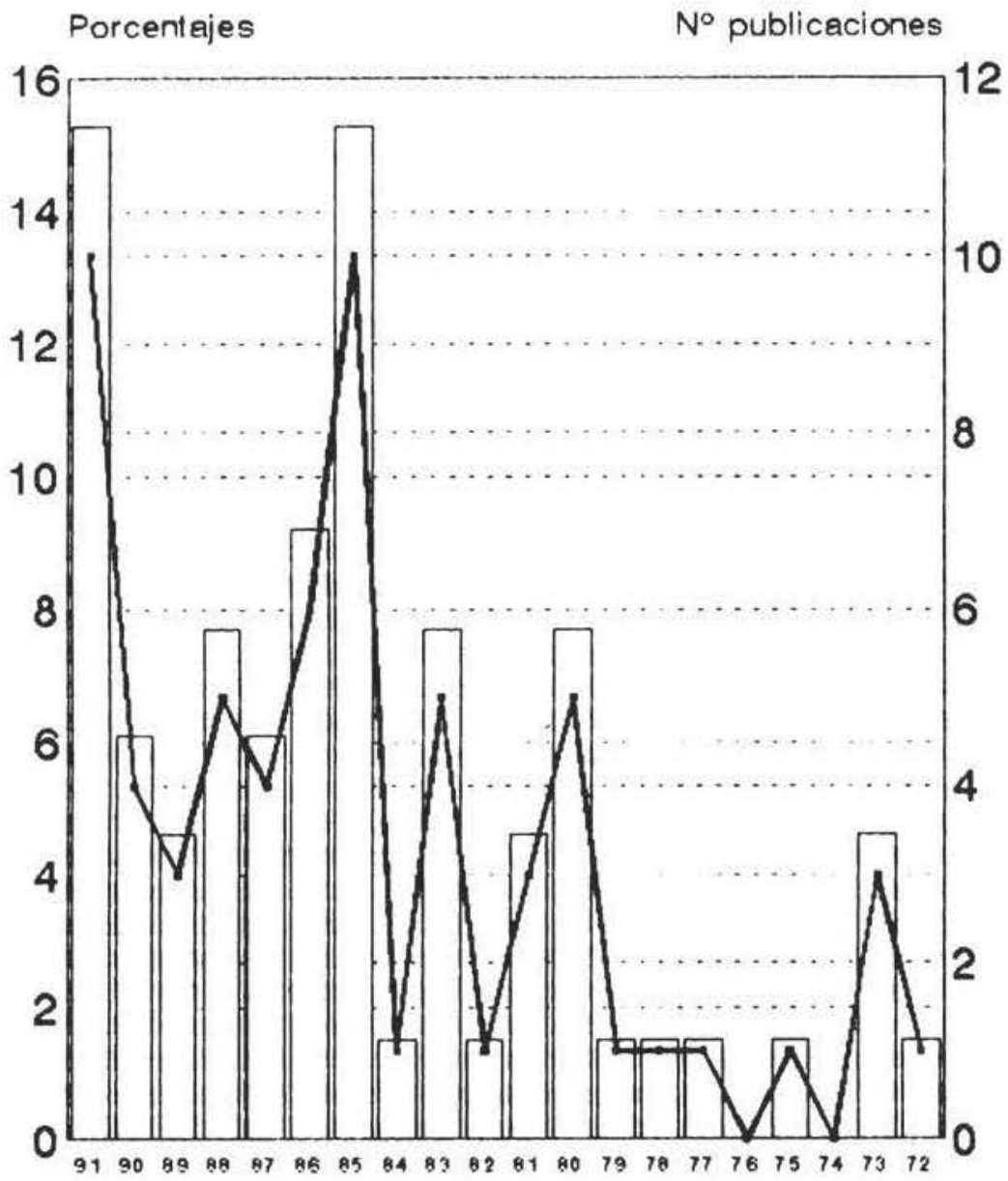

Años

Fig. 2. Publicaciones españolas sobre caracterización de cerámicas (Período 1972-1991). N. ${ }^{\circ}$ trabajos: 65 .

pecializadas en temas arqueométricos, podemos observar que apenas hay trabajos españoles sobre caracterización de cerámicas arqueológicas y los pocos que existen han sido publicados, salvo en alguna ocasión (Capel et al., 1985; Martín Socas, et a., 1989; Gerrard y Gutiérrez, 1991), no por arqueólogos sino por los propios especialistas (González et al., 1983; Gancedo et al., 1985; Vendrell-Saz et al., 1991). Asimismo, son pocos los autores extranjeros que han trabajado con materiales españoles, lo cual también puede ser indicativo del poco interés que se ha mostrado hacia ellos (Peacock, 1974; Picon, 1984; Tavares, 1984; Echallier y Jullien, 1985; Harrison et al., 1987: 80-83) y cuando lo han hecho ha sido porque necesitaban caracterizar estas producciones ya que les aparecían en las excavaciones de sus respectivos países (Bazzana et al., 1986; Demians et al., 1986). El caso contrario es toda una excepción (Vendrell-Sanz et al., 1989). Además, a todo esto hay que añadir que los dos únicos trabajos divulgativos sobre el tema, paradójicamente repetidos en dos publicaciones distintas, se deben a un autor suizo (Jornet, 1984 a y b). 
Todos estos trabajos que hemos ido viendo a lo largo del texto reflejan, como hemos comentado anteriormente, que esta clase de estudios todavía no se ha desarrollado en nuestro país con toda la amplitud de posibilidades que ofrece, cuestión que pone de manifiesto en nuestra opinión el escaso interés que han suscitado entre los arqueólogos españoles.

Buko, en un artículo de 1984 en donde reflexionaba sobre algunos de los problemas que presentaba la caracterización de cerámicas arqueológicas, distinguía tres tipos de aproximaciones en los trabajos que se habían publicado hasta la fecha. En la primera de ellas se incluyen aqueIlos estudios que intentan evaluar la capacidad y utilidad de una o varias técnicas de análisis utilizando material empírico. En general no suelen contribuir de manera importante a la problemática de identificar fuentes de materia prima aunque les reconoce su importancia metodológica. El segundo grupo de aproximaciones es el más generalizado. Engloba los estudios que tratan de establecer el modelo de producción local de un único lugar arqueológico mediante la aplicación de una técnica concreta y sobre el que se identifican los elementos foráneos. El tercero es sin duda el que menos atención ha recibido ya que requiere una estrategia de investigación a nivel regional. En este caso se intenta poner en relación las materias primas existentes en una región con las cerámicas arqueológicas que ha proporcionado (Buko, 1984: 349). En la arqueología española ha predominado, si seguimos la división que establece este autor, un tipo de aproximación que podríamos situar entre los dos primeros casos. Es decir, trabajos que utilizan sólo cierto material de un yacimiento determinado para mostrar la capacidad de la técnica o técnicas de análisis que han puesto en práctica e identificar sobre un modelo de producción local los elementos foráneos. Únicamente podríamos incluir dentro del tercer tipo de aproximaciones el trabajo llevado a cabo por el grupo de Granada en el estudio de las cerámicas neolíticas de esta provincia (Navarrete et al., 1991).

Estos trabajos muestran una serie de constantes ya planteadas por uno de nosotros (García Heras, 1992). Pueden resumirse en los puntos siguientes:

1) Existe una clara desconexión entre los propósitos arqueológicos y los relacionados con las técnicas de análisis, motivada en gran parte por la escasa colaboración entre el arqueólogo y el especialista y por la poca información experimental del primero. Esto hace que en muchas monografías los análisis cerámicos aparezcan como un simple apéndice al final de las mismas y con poco valor en las conclusiones globales. A veces son los propios especialistas los que publican por separado sus trabajos (Gracia, 1980; Gancedo et al., 1985; Pradell et al., 1991).

2) En muy pocas ocasiones se realiza una justificación de los métodos de análisis utilizados en función de los problemas a resolver, así como tampoco se explicitan los criterios seguidos a la hora de seleccionar las muestras a analizar. En algunos de ellos se analizan uno o dos fragmentos (Rincón et al., 1990; V. Galván, 1991). De esta forma resulta muy difícil hacer una valoración de los resultados.

3) Incidencia en los factores tecnológicos de la producción cerámica. Se muestra muy poco interés por integrar estos datos en la reconstrucción de patrones de comercio e intercambio, ni en analizar sus pautas de distribución. Se ignora por completo el papel social de la cerámica y aspectos como el de la especialización de su producción. De igual forma, no es corriente el uso de datos etnográficos de la zona en estudio como medio de obtener información acerca de la tecnología (Gerrard y Gutiérrez, 1988, 1991; Pradell et al., 1991).

4) En pocos trabajos (Martín Socas et al., 1985; Capel, 1986; Navarrete et al., 1991) se recurre a la toma de muestras actuales de arcilla como fuente de contrastación para la caracteri- 
zación. Igualmente. no es corriente la experimentación como medio de acercamiento a los problemas planteados en la manufacturación de cerámicas.

5) Falta de estudios globales de carácter regional en donde se relacionen las materias primas potencialmente utilizables de la región en estudio con las cerámicas proporcionadas por los diferentes yacimientos de la zona.

En cualquier caso, algunas de estas cuestiones tienen mucho más que ver con la propia dinámica de la investigación arqueológica española que lo que en sí representan dentro de este tipo de aproximación. No podemos olvidar que en los estudios sobre cerámica arqueológica todavía siguen prevaleciendo los criterios de forma y decoración con un único objetivo: la ubicación cronológica, y que por el momento la pasta que compone una cerámica raras veces se contempla interrelacionada con estos dos factores. Por ello, aún no es frecuente en nuestras publicaciones el uso de una lupa binocular a la hora de clasificar las cerámicas de un yacimiento, hecho que puede ser de gran ayuda para iniciar un estudio de caracterización o para contar con una base de datos preliminar de las características externas de las pastas cerámicas obtenidas por áreas geográficas y por períodos. Obviamente, estos condicionantes no representan precisamente un campo abonado para el desarrollo de estas técnicas. Hay también otras cuestiones. La creación de equipos interdisciplinares formados por arqueólogos y otros especialistas trabajando en los mismos programas de investigación, nunca han sido una constante hasta hace relativamente poco tiempo dentro de nuestra tradición arqueológica.

Dentro de este panorama creemos que en última instancia a quien nos corresponde reflexionar sobre este estado de cosas es a los propios arqueólogos y que las conclusiones deben extraerse desde nuestra propia disciplina. En nuestra opinión pensamos que las diferentes técnicas de caracterización pueden ofrecer muy buenos resultados siempre que se conozca cuál es la naturaleza de los problemas a resolver, las técnicas que pueden ayudar a solucionarlos y asumiendo las limitaciones que presentan. En este sentido sería interesante ampliar la colaboración entre el arqueólogo y los distintos especialistas y aumentar los programas integrados de investigación que conduzcan a la creación de más equipos interdisciplinares estables que contribuyan a la consolidación de la analítica ya existente y desarrollen aquellas técnicas que a pesar de su potencial aún no se han aplicado de forma generalizada en los estudios de caracterización de cerámicas (vid. fig. 1). Este último aspecto podría contribuir al desarrollo de toda la analítica relacionada con la caracterización de una manera más directa que el acceso comercial a estas técnicas, cuyos costos son en la mayoría de los casos muy elevados (Harbottle, 1982: 39). También podría contribuir a que sea el propio arqueólogo el que se especialice en estas técnicas y se implique directamente en los diferentes problemas planteados en los estudios de caracterización. Esta cuestión ha sido igualmente defendida por Vila y Estévez en un reciente artículo en donde exponían la necesidad de desarrollar las distintas ciencias auxiliares desde la misma arqueología dado que su enfoque actual se centra en el estudio de las relaciones económico-sociales de las comunidades del pasado y exige el desarrollo metodológico de nuevas líneas de investigación (Vila y Estévez, 1989).

Ahora bien, es necesario insistir en que las técnicas de caracterización no son un fin en sí mismo y que los análisis efectuados sobre las cerámicas arqueológicas tienen un escaso valor si no se integran en el marco de aproximaciones que contemplen el fenómeno de la cerámica como uno más de los factores que interactúan en el conjunto de las sociedades del pasado. Es importante también insistir en la necesidad de desarrollar este campo de investigacion dentro de la tra- 
dición arqueológica española ya que puede contribuir de manera decisiva a la solución de muchos de los interrogantes planteados por la cerámica de los diferentes períodos históricos. Por otro lado, no estaría de más insistir igualmente en la necesidad de concienciar a nuestros museos sobre el potencial que ofrecen este tipo de métodos, el cual justificaría sobradamente la destrucción en algunas ocasiones de una parte mínima del objeto y que, sin duda, nos ayudaría a perder ese culto casi místico que a veces se establece entre el investigador y sus objetos arqueológicos.

Por último, no queremos terminar estas líneas sin hacer una llamada de atención acerca de uno de los métodos de análisis que ha sido escasamente utilizado en España a pesar de que en otros países tiene una gran aceptación. Nos referimos al análisis de láminas delgadas a través del microscopio petrográfico, un método que combina estudios mineralógicos de composicion con estudios propiamente tecnológicos relacionados con el proceso de manufacturación de las cerámicas. Es un método que permite emprender, con unos costes asequibles, complejos y completos estudios sobre la procedencia de los materiales empleados en la elaboración de las cerámicas de uno o varios yacimientos siempre que se cuente con una buena información geológica del entorno.

\section{APÉNDICE: LOS MÉTODOS DE ANÁLISIS}

La composición mineralógica de una cerámica caracteriza a un lugar o a un área de manufactura. Básicamente hay dos tipos de análisis para conocer esta composición. El análisis mineralógico y el análisis de elementos químicos. Cada uno de ellos comprende toda una serie de técnicas que veremos a continuación. Algunas de estas técnicas, como podremos comprobar, también nos informan sobre la tecnología que se utilizó para transformar sus materias primas y convertirlas en un objeto cerámico.

La mayoría de los especialistas reconocen que ambos tipos de análisis deberían ser complementarios y que los resultados de unos deberían cotejarse con los resultados de los otros. En cualquier caso, la elección del método o métodos de estudio estará condicionada teóricamente por la naturaleza de los problemas que se quieran resolver, aunque desgraciadamente en esta elección también influyen otros condicionantes propios de la investigación, como pueden ser las disponibilidades presupuestarias o la existencia de laboratorios dotados con equipos tanto humanos como técnicos para utilizar cada método. Por este motivo, se hace indispensable una contínua colaboración entre el arqueólogo y el especialista. Que éste conozca cuál es la naturaleza de los métodos de análisis y qué tipo de cuestiones pueden resolver y que aquél comprenda ante qué tipo de datos se encuentra y qué analítica puede ofrecer. A pesar de todo este tipo de condicionantes, sería deseable que en los trabajos de caracterización se realizara siempre una justificación sobre el método elegido y sobre las razones que han influido en la elección de ese método con el fin de poder hacer una mejor valoración de los resultados.

En los estudios sobre composición de cerámicas se siguen siempre cuatro pasos fundamentales: 1) Selección de cerámicas a analizar. 2) Obtención de muestras de estas cerámicas. 3) Análisis de las muestras. 4) Interpretación de los resultados. La base sobre la que se sustentan las aproximaciones de procedencia es conocer la concentración característica de cada mineral o elemento químico de la arcilla que compone una cerámica procedente de un lugar conocido. De esta forma se compara su concentración con la de otros lugares conocidos. Por ello, como ya adelantábamos anteriormente, muchos autores insisten en que cuando se trata de identificar varios grupos de composiciones en un yacimiento arqueológico o en un área muy restringida, es necesario conocer también la composición de las arcillas susceptibles de uso en ese mismo yacimiento para realizar una caracterización completa de sus materiales y obtener unos datos más concluyentes sobre la posible procedencia autóctona o alóctona de ellos (Picon, 1973; Wilson, 1978; Echallier, 1984; Adan-Bayewitz y Perlman, 1985). 
En la aplicación de estas técnicas analíticas es importante tener en cuenta dos factores que a veces resultan ciertamente difíciles de evaluar. Por un lado, los cambios que han tenido lugar en los componentes de una cerámica durante su enterramiento. En este sentido todavía son pocos los estudios que han incidido en ello (Franklin y Vitali, 1985; Capel, 1986; Picon, 1987), aunque a nuestro modo de ver sería un aspecto importante a desarrollar. Por otro lado, los cambios sufridos por la materia prima durante la producción del artefacto. Para conseguir un conocimiento exhaustivo de estos cambios sería interesante desarrollar mucho más la vía de la experimentación con materiales actuales con el fin de observar su comportamiento ante estos procesos.

\section{LOS MÉTODOS DE ANÁLISIS MINERALÓGICO}

En general permiten recabar información acerca de los componentes cristalinos presentes en las cerámicas en forma de desgrasantes. Los principales métodos mineralógicos son el análisis de láminas delgadas con el microscopio petrográfico y la difractometría de rayos X. En la mayoría de los casos y a pesar de no ser un método propiamente mineralógico, se utiliza la Lupa Binocular como medio de realizar un primer acercamiento a los fragmentos cerámicos y efectuar la selección necesaria que dictaminará cuáles de ellos son los que presentan mejores características, según las cuestiones planteadas, para poder ser analizados por los diferentes métodos. La observación con lupa binocular consiste en examinar superficies y roturas frescas de las cerámicas. Con ello se pueden determinar aspectos relacionados con el acabado y la decoración y obtener una primera separación de grupos tecnológicos que ayude a centrar los estudios posteriores. Los aumentos que se utilizan (hasta $60 \mathrm{x}$ ) son sobradamente suficientes para realizar un estudio serio sobre decoraciones o trazas de útiles empleados en acabados, pero pueden llevar a engaño si se intenta hacer una interpretación mineralógica. En esta caso se hace necesario utilizar otras técnicas con resultados más precisos.

- Análisis de Láminas Delgadas y Microscopía Petrográfica: Este método consiste en confeccionar una lámina de unos 0,03 milímetros de grosor a partir de un fragmento cerámico, con lo cual es necesario cortar una mínima parte del mismo, pulirla y posteriormente adherirla a un portamuestras por medio de unas resinas especiales. Esta lámina se analiza a través de un microscopio petrográfico provisto de un dispositivo que polariza la luz y permite identificar los minerales según sus propiedades ópticas. Los análisis sobre lámina delgada pueden utilizarse en dos sentidos: 1) Para conocer los componentes minerales presentes en la pasta cerámica, ya sea en forma de desgrasantes añadidos intencionadamente o contenidos en la arcilla de forma natural. Los métodos que se emplean en este caso son los mismos que los utilizados por los geólogos para examinar rocas y minerales. 2) Para determinar las técnicas que se emplearon en la fabricación de la cerámica. En esta ocasión se combinan con las observaciones efectuadas con la lupa binocular, resultando de gran interés en el estudio de acabados, decoraciones, aspectos de la cocción, formas de modelar, etc.

El objetivo final de los análisis sobre lámina delgada es el de caracterizar mineralógicamente las cerámicas para con posterioridad poderlas asociar en grupos tecnológicos o poder hacer referencia al origen de las arcillas utilizadas en la fabricación de las mismas. Este segundo punto se revela bastante complejo puesto que de todos los minerales presentes en las cerámicas sólo algunos de ellos serán «caracterizadores» en relación con la geología del entorno. Para entendernos mejor, si en un yacimiento nos encontramos con cerámicas caracterizadas por la presencia de cuarzos, feldespatos y micas, estos resultados serán poco significativos si nos hallamos dentro de una región granítica de muchos $\mathrm{km}^{2}$, pero en cambio serán de gran valor los fragmentos de rocas volcánicas que puedan ser características por ejemplo de una zona volcánica determinada fuera de esta región. Todo esto hace que cuanto más «raros» sean los minerales presentes en la pasta más positivos sean los resultados. Esto hace también que el método sea menos útil cuanto más decantadas estén las pastas y sea más difícil identificar los desgrasantes, revelándose complementario para los análisis de cerámicas finas a torno (Courtois, 1976).

Uno de los problemas principales que presenta es la incapacidad de cuantificar objetivamente la pro- 
porción de los minerales presentes en las muestras, con la complicación que esto conlleva para posteriores tratamientos estadísticos de los datos. Sin embargo, y a pesar de los inconvenientes señalados, este método ha posibilitado excelentes estudios en países como Inglaterra o Francia con interesantes resultados sobre todo a la hora de trazar rutas de comercio de materiales cerámicos y de los productos que contenían (Echallier, 1982; Gosden, 1987; Nicholson, 1989). Para una más completa información acerca de las últimas aportaciones que se han realizado con este método puede consultarse el trabajo editado por Middleton y Freestone (1991).

En algunas ocasiones el análisis sobre lámina delgada no resulta demasiado concluyente cuando se trata de determinar la naturaleza de inclusiones demasiado homogéneas, como puede ser el caso de la utilización de desgrasantes compuestos por arena. Para resolver esta cuestión se ha aplicado el Análisis de Minerales Pesados (HMA), consistente en separar dichos minerales de la pasta reducida a polvo y diluida en una solución especial. De esta forma se comparan las concentraciones de la muestra con las de los posibles sedimentos de los que proceden. Aunque el método arrojó buenos resultados en estudios relacionados con la cerámica romana inglesa (Peacock, 1967; Williams, 1977), actualmente es una técnica de análisis que apenas se utiliza.

- Difracción de Rayos X (XRD): Es un método que se complementa muy bien con el anterior ya que permite detectar aquellos elementos cristalinos que no han podido ser observados con el microscopio petrográfico. Ha sido ampliamente utilizado en todos los estudios sobre caracterización. Consiste en bombardear una muestra, previamente reducida a polvo, con rayos X. Estos rayos son difractados por cada sustancia cristalina presente en la muestra de una forma característica lo cual permite la identificación de los componentes minerales de la pasta. Su presencia sólo puede estimarse en términos semicuantitativos, lo cual representa una de sus principales limitaciones. Resulta muy apropiado para conocer la composición de las arcillas aunque la mayor parte de las veces éstas ya hayan perdido su estructura cristalina a través de la cocción. Con este método se pueden hacer estimaciones sobre la temperatura alcanzada en la cocción basándose en la presencia de minerales «neoformados» que aparecen por transformación de otros que estaban presentes en la pasta inicial de la arcilla cuando se alcanzan ciertas temperaturas, aunque éste no es el único factor que produce dichas transformaciones. También pueden influir las características de cada mineral, la atmósfera de cocción u otras. Algunos de los fundamentos del método aplicado a cerámicas prehistóricas pueden ampliarse en los trabajos de Weymouth (1973) y Echallier (1981).

- Microscopía Electrónica (EM): Los microscopios electrónicos utilizan haces de electrones lanzados a gran velocidad, lo cual permite ver los objetos con unos aumentos que pueden llegar a ser del orden de $100.000 \mathrm{x}$. Un aspecto tan importante como los aumentos que se logran es el de la gran profundidad de çampo que puede alcanzar. Esto permite estudiar ciertas microestructuras incluso con poca magnificación. Normalmente suelen tener acoplada una microsonda que puede realizar análisis químicos de los elementos mostrados en la imagen. Este dispositivo ha posibilitado algunos trabajos de gran interés (Kamilli y Lamberg-Karlovsky, 1979; Freestone, 1982). Una de sus mayores ventajas consiste en poder observar la estructura de los microcristales de la arcilla si ésta no ha sido transformada del todo durante la cocción, pudiéndose identificar de esta forma el tipo del que se trata.

Hay dos tipos principales de microscopios electrónicos: 1) El Microscopio Electrónico de Transmisión (TEM), que se emplea sobre todo para el reconocimiento de los minerales mediante la difracción de los electrones dentro del área que se selecciona. 2) El Microscopio Electrónico de Barrido (SEM), utilizado generalmente para el reconocimiento morfológico de las pastas cerámicas, analizando su porosidad, textura y microestructura (Tite y Maniatis, 1975; Tite et at., 1982).

Entre sus inconvenientes puede señalarse su elevado costo. Por esta razón su utilización suele restringirse a la resolución de problemas concretos como puede ser el análisis de engobes, colorantes, pinturas o identificar la composición de determinadas partículas de la pasta.

Como hemos podido ver, los principales problemas que presentan los métodos de análisis mineralógico se relacionan con la cuantificación de los resultados. En el caso de las láminas delgadas se han intentado resolver mediante técnicas de "conteo de puntos», no demasiado satisfactorias por el momento. 
Algunos autores prefieren por ello reflejar los resultados en términos de «estimación de abundancia" en lugar de porcentajes. Por lo que se refiere a la difracción de rayos X, en las cuantificaciones se emplean porcentajes semicuantitativos aproximativos, ya que sólo es posible hacer un conteo de la materia cristalina que se ha podido identificar. Esto hace que por ahora los resultados of recidos por los diferentes laboratorios no puedan ponerse en relación.

Es importante hacer hincapié en el enorme potencial que ofrece por sí misma la microscopía petrogrática para llegar a resolver importantes problemas en la composición de desgrasantes y en la determinación de áreas suministradoras de materia prima, aunque a veces haya que buscar el apoyo de otros análisis ya sean químicos o mineralógicos. Además, es el sistema que tiene los costos menos elevados a pesar de que exige un aprendizaje prolongado para poder llegar a distinguir los minerales presentes en las pastas cerámicas ya que a veces no presentan las mismas características que en las rocas naturales.

\begin{tabular}{|c|c|c|c|c|c|c|c|}
\hline Método & Carácter & $\begin{array}{l}\text { Cantidad } \\
\text { muestra }\end{array}$ & Determinación & Utilidad & Precisión & Costos & Limitaciones \\
\hline Lupa Binocular & No destructivo. & - & $\begin{array}{l}\text { Aspecto externo } \\
\text { e interno pasta }\end{array}$ & $\begin{array}{l}\text { - Imprescindible } \\
\text { para seleccionar } \\
\text { muestras a anali- } \\
\text { zar. } \\
\text { - Detecta huellas } \\
\text { proceso manu- } \\
\text { facturación y de- } \\
\text { coraciones. }\end{array}$ & $\begin{array}{l}\text { Según experien- } \\
\text { cia. }\end{array}$ & $\$$ & $\begin{array}{l}\text { No concluyente } \\
\text { en determinacio- } \\
\text { nes mineralógi- } \\
\text { cas. }\end{array}$ \\
\hline $\begin{array}{l}\text { Lámina Delgada } \\
\text { y Microscopía } \\
\text { Petrográfica }\end{array}$ & Destructivo & $4 \times 4 \mathrm{~cm}$. & $\begin{array}{l}\text { Cualitativa de } \\
\text { minerales }\end{array}$ & $\begin{array}{l}\text { - Conocer com- } \\
\text { ponentes minera- } \\
\text { les. } \\
\text { - Conocer técni- } \\
\text { cas de manufac- } \\
\text { turación }\end{array}$ & $\begin{array}{l}\text { Según experien- } \\
\text { cia. }\end{array}$ & $\$ \$$ & $\begin{array}{l}\text { - Problemas para } \\
\text { cuantificar mine- } \\
\text { rales. } \\
\text { - A veces mine- } \\
\text { rales determina- } \\
\text { dos no son carac- } \\
\text { terizadores de re- } \\
\text { gión en estudio. }\end{array}$ \\
\hline $\begin{array}{l}\text { Difracción de } \\
\text { Rayos X (XRD) }\end{array}$ & Destructivo & $2.5 \mathrm{gr}$. & $\begin{array}{l}\text { Cualitativa y se- } \\
\text { micuantitativa de } \\
\text { minerales }\end{array}$ & $\begin{array}{l}\text { - Determinar mi- } \\
\text { nerales no visi- } \\
\text { bles con lámina } \\
\text { delgada. } \\
\text { - Conocer tem- } \\
\text { peratura de coc- } \\
\text { ción. }\end{array}$ & Alta & $\$ \$$ & $\begin{array}{l}\text { Porcentajes se- } \\
\text { micuantitativos } \\
\text { de minerales pre- } \\
\text { sentan problemas } \\
\text { para tratamiento } \\
\text { estadistico. }\end{array}$ \\
\hline $\begin{array}{l}\text { Microscopía } \\
\text { Electrónica (EM) }\end{array}$ & Destructivo & $5 \cdot 10 \mathrm{mg}$. & $\begin{array}{l}\text { Cualitativa y } \\
\text { cuantitativa de } \\
\text { minerales de mi- } \\
\text { croestructuras. }\end{array}$ & $\begin{array}{l}\text { Resolución de } \\
\text { problemas con- } \\
\text { cretos en engo- } \\
\text { bes, colorantes, } \\
\text { pinturas o parti- } \\
\text { culas determina- } \\
\text { das. }\end{array}$ & Alta & \$\$\$ & - \\
\hline
\end{tabular}

Fig. 3. Métodos de análisis mineralógico.

Costos. \$\$: Elevados. \$\$: Intermedios. \$: Bajos. 


\section{LOS MÉTODOS DE ANÁLISIS DE ELEMENTOS QUÍMICOS}

La mayoría de los métodos de análisis que determinan los elementos químicos que contiene la pasta de una cerámica están capacitados para medir la concentración tanto de elementos mayoritarios como minoritarios, así como de elementos traza. Como mencionamos anteriormente, estos análisis deberían utilizarse para complementar la información que nos han proporcionado los métodos mineralógicos. De todas formas, en muchas ocasiones las muestras cerámicas son tan homogéneas desde el punto de vista mineralógico que sólo el análisis de sus elementos químicos puede proporcionarnos una caracterización fiable (Shotton y Hendry, 1979). En estos casos, que en realidad conforman la amplia mayoría de sus aplicaciones arqueológicas, se recurre a medir la proporción de elementos traza que presentan las muestras, dado que los elementos mayoritarios no nos ayudarían de forma concluyente para caracterizarlas por su relativa presencia en todos los compuestos naturales. Los elementos traza aparecen en muy pequeñas cantidades y sus concentraciones se miden en partes por millón (ppm) e inferiores. Los análisis sobre elementos traza se basan en la asunción de que su presencia en un objeto es única e irrepetible y depende de la génesis y origen de sus materias primas y de los métodos empleados en su elaboración y tratamiento (De Bruin et al., 1976). Podríamos decir que estos elementos son las huellas digitales de un objeto arqueológico.

Es importante resaltar que las determinaciones químicas en la composición de una cerámica son resultado de la correlación estadística de las concentraciones de cada elemento. Su grado de precisión se mide en términos de probabilidad y como tal deben interpretarse sus resultados. En los estudios de procedencia de cerámicas esto se traduce en que una muestra aislada podrá tener un índice alto de probabilidad de lugares en los que no se manufacturó, pero no se podrá afirmar, sin repertorios de referencia, cuál es su lugar de manufactura (Harbottle, 1982).

Existen, como veremos a continuación, varios métodos para medir la concentración de estos elementos. Cada uno difiere en costos, en sensibilidad y precisión para medir cierta cantidad de elementos y en la necesidad de destruir o no parte de la muestra. Aunque se han producido grandes avances en este tipo de analítica, todavía en la actualidad no se han resuelto algunos problemas importantes, como puede ser la puesta en común de los parámetros empleados en cada laboratorio para estimar las distribuciones de cada elemento. Este punto debería tenerse en cuenta si se pretenden comparar los resultados obtenidos por diferentes laboratorios con los mismos materiales.

- Análisis de Activación Neutrónica (NAA): Fue uno de los primeros métodos que se empleó en el análisis de cerámicas arqueológicas (Sayre y Dodson, 1957). Para muchos autores es el método ideal para los estudios sobre procedencia por su precisión para determinar un gran número de elementos (Picon, 1991). Es un análisis químico isotópico basado en la medida de la radiactividad artificial que emite una muestra al ser bombardeada con neutrones en un reactor nuclear. Por este procedimiento la muestra emite un espectro de rayos gamma. Como cada elemento químico tiene un nivel característico de estos rayos, según sea el índice de energía emitida el método detecta la presencia de cada elemento. Su intensidad informa sobre la cantidad contenida.

Es un método muy preciso para determinar muchos elementos de una sola vez. En un principio se utilizaron detectores de centelleo que sólo permitían la determinación de unos pocos elementos. Actualmente se utilizan detectores de alta resolución que pueden detectar una gran cantidad de éstos. Consta de dos tipos de técnicas: la Activación Radioquímica (RNAA), en donde la muestra se analiza en solución y requiere la destrucción de una parte mínima del objeto ( $5 \mathrm{mg}$.); y la Activación Instrumental (INAA), que no requiere destrucción de la muestra. En ambos se utilizan elementos estándar sobre los que se basan las mediciones.

Su ventaja principal reside en que determina tanto cualitativa como cuantitativamente un elevado número de elementos y en que una de sus técnicas no es destructiva. Entre las desventajas que presenta están el elevado coste tanto económico como de tiempo de realización, el tener acceso a un reactor nuclear y el que las muestras analizadas pueden contener una reducida cantidad de radiactividad durante algún tiempo. Algunas de las más recientes aportaciones que se han llevado a cabo con este método utilizando cerámicas arqueológicas, han sido recogidas en el trabajo editado por Hughes et al. (1991). 
- Espectrometría de Emisión Óptica (OES): Sus fundamentos consisten en excitar a los electrones de los átomos vaporizando la muestra con una chispa eléctrica de alto voltaje en un arco de carbono. De esta forma cada elemento emite una luz con una determinada longitud de onda. El método registra las líneas que emiten los elementos a partir de una muestra estándar sobre la que se basan las mediciones. Los resultados se expresan en porcentajes para los elementos comunes y en ppm para trazas. Determina un número elevado de elementos pero no es muy preciso. Además, presenta problemas importantes con los silicatos e interferencias entre elementos con longitudes de onda muy similares. Es un método destructivo que ha sido muy utilizado en la primera etapa de análisis cerámicos para determinar composiciones elementales (Catling, 1963; Catling y Jones, 1977). En la actualidad poco a poco se va desplazando en favor de la Espectrometría de Absorción Atómica y de Plasma de Acoplamiento Inductivo.

- Espectrometría de Absorción Atómica (AAS): Tiene el mismo principio que la Espectrometría de Emisión Óptica aunque aquí la muestra se disuelve en un ácido y se excita con una llama producida en un horno especial. También es un método destructivo. Es muy preciso midiendo elementos mayores y cuando se trata de medir un solo elemento, aunque su precisión disminuye con los elementos traza (Bomgardner, 1981). Es una técnica muy costosa en tiempo para efectuar mediciones de varios elementos. Tiene grandes ventajas a la hora de detectar metales no ferroros como el cobre y elementos con bajo número atómico como el litio y el sodio. Algunas cerámicas británicas romanas han sido analizadas con este procedimiento (Tubb et al., 1980).

- Espectrometría de Plasma de Acoplamiento Inductivo (ICPS): Sigue el mismo principio que la Espectrometría de Absorción Atómica y la de Emisión Óptica. En este caso la muestra se excita en una atmosfera de gases ionizados mediante una inducción eléctrica. Su ventaja principal reside en que reduce los problemas de interferencias entre elementos que presentaba la Espectrometría de Emisión Óptica para determinar composiciones elementales. Su precisión, por tanto, es elevada. Es un método destructivo. El trabajo de Hughes et al. (1991) recoge igualmente algunas de las más recientes aportaciones.

- Espectrometría de Fluorescencia de Rayos $X(X R F)$ : Ha sido uno de los métodos más utilizados en los análisis cerámicos por su bajo costo y por tener una precisión relativamente alta (Stern y Descoeudres, 1977; Culbert y Schwalbe, 1987). En esta técnica la muestra se irradia con rayos X que excitan los electrones de la superficie. Cuando cesa la irradiación los electrones vuelven a su posición original, pero antes emiten una serie de rayos $\mathrm{X}$ secundarios of fluorescentes. Cada elemento emite una longitud de onda característica y por este procedimiento pueden detectarse y cuantificarse. Los elementos se miden sobre la base de una muestra estándar. Es un método no destructivo pero sólo analiza la composición de la superficie del material. Si se desea examinar el interior es necesario destruir la muestra. Este método ha resultado ser muy útil en el análisis de la composición de vidriados.

- Emisión de Rayos X Inducida por Protones (PIXE): Es una técnica muy similar a la anterior y tiene sus mismos principios. Todavía no ha sido muy utilizada en análisis cerámicos. Determina un gran número de elementos con bastante precisión. Una de sus ventajas principales frente a otros métodos es que puede medir muchas muestras en un tiempo relativamente corto (Renfrew y Bahn, 1991: 316-317; Rice, 1987: 398).

- Emisión de Rayos Gamma Inducida por Protones (PIGME): Sus principios son muy similares a los del análisis por Activación. Se suele emplear como apoyo de la Espectrometría de Fluorescencia de Rayos X para detectar elementos con bajo peso atómico como la fluorina, el sodio y el aluminio que por este procedimiento no se miden con mucha precisión (Renfrew y Bahn, 1991: 316-317; Rice, 1987: $400)$.

Como hemos podido ver, la mayoría de técnicas de análisis de elementos traza requieren un instrumental de gran precisión y tienen unos costes ciertamente elevados. Debemos insistir nuevamente en la planificación de la estrategia de investigación ante problemas arqueológicos y en el contínuo diálogo entre los especialistas y el arqué́logo. Sólo así podremos conseguir que la inversión realizada resulte rentable desde el punto de vista de los objetivos a conseguir. En algunos casos puede darse la circunstancia de que los análisis de elementos traza no sean necesariamente el mejor procedimiento con los datos dis- 
ponibles o con la naturaleza del problema a resolver (Bishop et al., 1982). Un buen análisis mineralógico puede dar muy buenos resultados.

Los elementos traza pueden ser útiles en general para distinguir los orígenes de arcillas cercanas y muy similares en estudios regionales o para agrupar muestras sobre la base de las concentraciones de dos o tres elementos característicos (Renfrew y Bahn, 1991: 317-318).

\begin{tabular}{|c|c|c|c|c|c|c|c|}
\hline Método & Carácter & $\begin{array}{c}\text { Cantidad } \\
\text { muestra }\end{array}$ & Determinación & Utilidad & Precisión & Costos & Limitaciones \\
\hline $\begin{array}{l}\text { Análisis de Acti- } \\
\text { vación Neutróni- } \\
\text { ca (NAA) }\end{array}$ & $\begin{array}{l}\text { - Radio-química } \\
\text { (RNAA). Des- } \\
\text { tructivo. } \\
\text { - Instrumental } \\
\text { (INAA). No des- } \\
\text { tructivo. }\end{array}$ & $5 \mathrm{mg}$ en RNAA & \begin{tabular}{|l|} 
Cualitativa y \\
cuantitativa de \\
varios elementos.
\end{tabular} & $\begin{array}{l}\text { Clasifica grupos } \\
\text { de objetos rela- } \\
\text { cionados entre sí }\end{array}$ & Alta $\pm 5 \%$ & $\$ \$ \$$ & $\begin{array}{l}\text { - Muestra puede } \\
\text { contener pequeña } \\
\text { cantidad de ra- } \\
\text { diactividad du- } \\
\text { rante algún tiem- } \\
\text { po. } \\
\text { - Se necesita un } \\
\text { reactor nuclear. }\end{array}$ \\
\hline $\begin{array}{l}\text { Espectrometría } \\
\text { de Emisión Ópti- } \\
\text { ca (OES) }\end{array}$ & Destructivo & $5.10 \mathrm{mg}$. & \begin{tabular}{|l|} 
Cualitativa y \\
cuantitativa de \\
varios elementos.
\end{tabular} & $\begin{array}{l}\text { Conocer compo- } \\
\text { siciones elemen- } \\
\text { tales }\end{array}$ & Baja $25 \%$ & $\$$ & $\begin{array}{l}\text { - No útil son sili- } \\
\text { catos. } \\
\text { - Interferencias } \\
\text { entre elementos. }\end{array}$ \\
\hline $\begin{array}{l}\text { Espectrometría } \\
\text { de Absorción } \\
\text { Atómica (AAS) }\end{array}$ & Destructivo & $1-10 \mathrm{mg}$. & \begin{tabular}{|l|} 
Cualitativa y \\
cuantitativa de \\
varios elementos
\end{tabular} & $\begin{array}{l}\text { Detección meta- } \\
\text { les no ferrosos y } \\
\text { elementos con } \\
\text { bajo número ató- } \\
\text { mico. }\end{array}$ & $\begin{array}{l}\text { - Alta para un } \\
\text { solo elemento } \pm \\
1 \% \\
\text { - Media para tra- } \\
\text { zas } \pm 15 \%\end{array}$ & $\$ \$ \$$ & $\begin{array}{l}\text { Costoso en tiem- } \\
\text { po para medir } \\
\text { varios elementos. }\end{array}$ \\
\hline $\begin{array}{l}\text { Espectrometría } \\
\text { de Plasma de } \\
\text { Acoplamiento } \\
\text { Inductivo (ICPS) }\end{array}$ & Destructivo & $10 \mathrm{mg}$ & \begin{tabular}{|l|} 
Cualitativa y \\
cuantitativa de \\
varios elementos
\end{tabular} & $\begin{array}{l}\text { Reduce proble- } \\
\text { mas de interfe- } \\
\text { rencias entre ele- } \\
\text { mentos en com- } \\
\text { posiciones ele- } \\
\text { mentales. }\end{array}$ & Alta $\pm 5 \%$ & $\$ \$ \$$ & - \\
\hline $\begin{array}{l}\text { Espectrometría } \\
\text { de fluorescencia } \\
\text { de Rayos X } \\
\text { (XRF) }\end{array}$ & $\begin{array}{l}\text { - No destructivo } \\
\text { en superficie. } \\
\text { - No destructivo } \\
\text { en interior. }\end{array}$ & $5.10 \mathrm{mg}$ & \begin{tabular}{|l|} 
Cualitativa y \\
cuantitativa de \\
varios elementos
\end{tabular} & $\begin{array}{l}\text { - Conocer com- } \\
\text { posiciones ele- } \\
\text { mentales. } \\
\text { - Conocer com- } \\
\text { posiciones de vi- } \\
\text { driados }\end{array}$ & Alta $\pm 2.5 \%$ & $\$$ & $\begin{array}{l}\text { Debe destruirse } \\
\text { muestra para } \\
\text { analizar interior. }\end{array}$ \\
\hline $\begin{array}{l}\text { Emisión de Ra- } \\
\text { yos X Inducida } \\
\text { por Protones } \\
\text { (PIXE) }\end{array}$ & Destructivo & $5 \mathrm{mg}$ & \begin{tabular}{|l|} 
Cualitativa y \\
cuantitativa de \\
varios elementos
\end{tabular} & $\begin{array}{l}\text { Mide gran núme- } \\
\text { ro de muestras } \\
\text { en poco tiempo }\end{array}$ & Alta $5 \%$ & $\$ s \$$ & - \\
\hline $\begin{array}{l}\text { Emisión de Ra- } \\
\text { yos Gamma In- } \\
\text { ducida por Pro- } \\
\text { tones (PIGME) }\end{array}$ & Destructivo & $5 \mathrm{mg}$ & $\begin{array}{l}\text { Cualitativa y } \\
\text { cuantitativa de } \\
\text { elementos } \\
\text { concretos }\end{array}$ & $\begin{array}{l}\text { Apoyo en ele- } \\
\text { mentos de bajo } \\
\text { peso atómico en } \\
\text { XRF. }\end{array}$ & Alta $5 \%$ & $\$ \$ \$$ & - \\
\hline
\end{tabular}

Fig. 4. Métodos de análisis de elementos químicos.

Costos. \$\$: Elevados. \$: Bajos. 


\section{OTROS MÉTODOS DE ANÁLISIS}

En este apartado hemos incluido aquellos métodos que por sus características no pertenecen a ninguno de los grupos de análisis anteriores. En general son técnicas que se utilizan o bien para la resolución de problemas puntuales o para apoyar los resultados de alguno de los métodos que hemos comentado.

- Análisis Térmico Diferencial (DTA): Permite medir las alteraciones que sufre una muestra determinada a lo largo del calentamiento producido en un horno por comparación con una muestra inerte. Durante el calentamiento, los componentes sufren una serie de transformaciones físicas que se traducen en deshidrataciones a bajas temperaturas, desorganizaciones estructurales $y$, a temperaturas elevadas, del orden de los 700 a $1.000^{\circ} \mathrm{C}$, recristalizaciones. En la práctica, la interpretación de los diagramas que ofrecen las cerámicas se torna muy complicada, ya que las cerámicas son cuerpos muy complejos, por lo que se utiliza casi exclusivamente para determinar las temperaturas de combustión de la materia orgánica presente en algunas de ellas (Kingery, 1974).

- Dilatometría: Consiste en medir las variaciones volumétricas que sufren las cerámicas a lo largo de su calentamiento como consecuencia de las dilataciones y contracciones que experimentan debidas, entre otras causas, a la pérdida de agua de constitución y a las transformaciones en las estructuras arcillosas. Ha sido empleado durante mucho tiempo para evaluar las temperaturas de cocción (Tite, 1969). Principalmente se basa en el hecho de que las cerámicas durante su cocción sufren un proceso de «sinterizado» (densificación). Cuando se sobrepasa la temperatura que alcanzó la cerámica en su cocción original el proceso de sinterizado comienza de nuevo, produciéndose entonces una importante contracción. Es importante resaltar que cualquier método que calcula la temperatura de cocción lo hace sobre la temperatura máxima alcanzada, la cual tiene una importancia relativa, pues muchas veces una cocción a baja temperatura con un enfriamiento prolongado y un buen control tiene mucha más calidad técnica que una cocción a muy alta temperatura pero descontrolada.

- Análisis Textural (TA): Es un método que utiliza las imágenes digilizadas de las láminas delgadas. Estas imágenes son tratadas posteriormente con un programa informático con el fin de calcular la proporción de los desgrasantes presentes en la pasta y su distribución por tamaños, sin hacer referencia a las características mineralógicas de los mismos. Es una técnica que en cierta medida intenta superar los problemas de cuantificación existentes en la Microscopía Petrográfica (Darvill y Timby, 1982; Middleton et al., 1985). Su mayor ventaja reside en que puede llegar a separar grupos de cerámicas muy parecidas en su composición mineralógica por pertenecer a una región geológica muy homogénea, atendiendo a las características litológicas y sedimentológicas de sus desgrasantes. Una de sus principales desventajas es que exige la utilización de equipos informáticos muy complejos y programas específicos creados para tal fin.

- Espectroscopía Mösshauer: Es un análisis espectroscópico de resonancia en donde se mide la radiación de los rayos gamma absorbida por los núcleos de los átomos de la muestra. Sobre todo es útil para estudiar aquellos materiales que contengan compuestos o minerales de hierro, como ocurre con la mayoría de las cerámicas. En este caso se determinan las fases que contienen este mineral en las arcillas observándose su comportamiento durante la cocción. Este método es muy preciso cuando se trata de determinar la procedencia de las arcillas, cuyas diferentes localizaciones contienen distintas proporciones en los minerales y compuestos férricos. Si el espectro se realiza por transmisión es necesaria la destrucción de una pequeña cantidad de la muestra (100 mg). En cambio, si se lleva a cabo por reflexión no hace falta destruir el fragmento aunque su precisión disminuye al no penetrar en el interior del objeto. Sus dos principales desventajas radican en el alto coste que presenta y en la cantidad de tiempo necesaria para realizar un espectro (alrededor de 40 horas). Para más información acerca de este método pueden consultarse los trabajos de la española Gracia (1980) y de Maniatis et al. (1982).

Existen otros métodos de análisis en los cuales no vamos a insistir, ya sea porque por el momento todavía no se han aplicado demasiado en los análisis cerámicos, como es el caso de la Espectroscopía de Infrarrojos, o porque su potencial con respecto a las cerámicas se halla aún en un estado de experimentación, como ocurre con los Métodos Radiográficos (Carr, 1990; Rice, 1987: 403). 


\begin{tabular}{|l|l|l|l|l|l|l|l|}
\hline \multicolumn{1}{|c|}{ Método } & \multicolumn{1}{|c|}{ Carácter } & \multicolumn{1}{|c|}{$\begin{array}{c}\text { Cantidad } \\
\text { muestra }\end{array}$} & Determinación & \multicolumn{1}{|c|}{ Utilidad } & Precisión & \multicolumn{1}{|c|}{ Costos } & Limitaciones \\
\hline $\begin{array}{l}\text { Análisis Térmico } \\
\text { Diferencial } \\
\text { (DTA) }\end{array}$ & No destructivo & - & $\begin{array}{l}\text { Alteraciones de } \\
\text { componentes por } \\
\text { calentamiento. }\end{array}$ & $\begin{array}{l}\text { Conocer tempe- } \\
\text { raturas de com- } \\
\text { bustión de mate- } \\
\text { ria orgánica. }\end{array}$ & $\begin{array}{l}\text { Difícil de esti- } \\
\text { mar. }\end{array}$ & $\$ \$ \$$ & $\begin{array}{l}\text { Difícil interpreta- } \\
\text { ción diagramas } \\
\text { de cerámica }\end{array}$ \\
\hline Dilatometría & No destructivo & - & $\begin{array}{l}\text { Variaciones vo- } \\
\text { lumétricas de } \\
\text { componentes por } \\
\text { calentamiento. }\end{array}$ & $\begin{array}{l}\text { Conocer tempe- } \\
\text { raturas de coc- } \\
\text { ción. }\end{array}$ & Alta & $\$ \$$ & $\begin{array}{l}\text { Estimaciones } \\
\text { temperaturas de } \\
\text { cocción sobre } \\
\text { temperatura má- } \\
\text { xima alcanzada }\end{array}$ \\
\hline $\begin{array}{l}\text { Análisis Textural } \\
\text { (TA) }\end{array}$ & Destructivo & $\begin{array}{l}\text { Como en lámina } \\
\text { delgada }\end{array}$ & $\begin{array}{l}\text { Cuantitativa de } \\
\text { minerales. }\end{array}$ & $\begin{array}{l}\text { Separación de } \\
\text { grupos homogé- } \\
\text { neos de cerámi- } \\
\text { cas. }\end{array}$ & $\begin{array}{l}\text { Según equipo in- } \\
\text { formático. }\end{array}$ & $\$ \$ \$$ & $\begin{array}{l}\text { Utiliza equipos } \\
\text { informátios com- } \\
\text { plejos }\end{array}$ \\
\hline $\begin{array}{l}\text { Espectroscopía } \\
\text { Mössbauer }\end{array}$ & $\begin{array}{l}\text { - Destructivo por } \\
\text { transmisión. } \\
\text { - No destructivo } \\
\text { por reflexión. }\end{array}$ & $\begin{array}{l}100 \text { mg para es- } \\
\text { pectroscopía por } \\
\text { transmisión. }\end{array}$ & $\begin{array}{l}\text { Cualitativa y } \\
\text { cuantitativa de } \\
\text { minerales y com- } \\
\text { puestos férricos. }\end{array}$ & $\begin{array}{l}\text { Conocer proce- } \\
\text { dencia de arci- } \\
\text { Ilas. }\end{array}$ & Alta & $\$ \$ \$$ & $\begin{array}{l}\text { Alrededor de 40 } \\
\text { horas por espec- } \\
\text { tro. }\end{array}$ \\
\hline
\end{tabular}

Fig. 5. Otros métodos de análisis

Costos. \$\$: Elevados. \$\$: Intermedios. \$: Bajos.

\section{CONCLUSIONES}

Como hemos ido viendo a lo largo de estas páginas, las técnicas de caracterizacion de cerámicas arqueológicas se han convertido en los últimos años en uno de los medios más consistentes de aproximación a fenómenos tales como el origen y procedencia de las materias primas que constituyen una cerámica o los procesos de su manufacturación, los cuales pueden proporcionarnos información muy valiosa sobre su forma de producción y sobre sus patrones de comercio e intercambio.

Los métodos de análisis tratan de conocer esencialmente cuál es la composición de los materiales de una cerámica, qué modificaciones pueden haber sufrido durante su elaboración y cómo pueden relacionarse con el entorno geológico en donde se ha hallado la cerámica. Para ello existen básicamente dos tipos de técnicas: la técnica de análisis mineralógico, que determina los componentes minerales presentes en las muestras, y la técnica de análisis de elementos químicos, cuyos objetivos están encaminados a determinar las concentraciones de estos elementos muchas veces presentes sólo en forma de trazas, es decir, concentraciones en partes por millón (ppm) e inferiores. Dada la naturaleza de estos métodos de análisis, su elevado costo y su alta complejidad en algunas ocasiones, se hace necesaria una contínua colaboración entre el arqueólogo y los diferentes especialistas tanto a la hora de diseñar la investigación como a la hora de formular las cuestiones que se pretenden resolver.

Un repaso a la bibliografía que hasta el momento se ha producido en nuestro país sobre este tema, nos hace comprobar que este tipo de analítica todavía no se ha desarrollado plenamente 
dentro de la investigación arqueológica española teniendo en cuenta el enorme potencial de estudio que ofrece. La aproximación que ha predominado en los diferentes trabajos se caracteriza por utilizar sólo cierto material de un yacimiento determinado con el fin de mostrar la capacidad de las técnicas de análisis utilizadas e identificar los elementos foráneos estableciendo un modelo de producción local. Algunas de las constantes que presentan estos trabajos pueden resumirse en:

- Escasa colaboración entre el arqueólogo y el analista.

- Desconexión entre los problemas arqueológicos y las técnicas de análisis utilizadas.

- Falta de justificación de los métodos de análisis empleados.

- Falta de justificación en los criterios seguidos para seleccionar las muestras a analizar.

- Incidencia en los factores tecnológicos de la producción cerámica.

- Falta de integración de los análisis en modelos generales de estudio del fenómeno cerámico.

- Escaso desarrollo de la experimentación como fuente de contrastación para la caracterización.

- Escasa utilización de datos etnográficos.

- Ausencia de estudios regionales.

Constantes que, en nuestra opinión, se deben al escaso interés que este tipo de aproximación ha tenido entre los arqueólogos españoles, al predominio en los estudios de cerámica prehistórica de criterios como los de forma y decoración por considerarlos buenos indicadores cronológicos y a la falta de equipos interdisciplinares estables que trabajen en los mismos programas de investigación.

Por todo ello creemos necesario una verdadera concienciación desde la propia arqueología del papel que pueden jugar estas técnicas en la resolución de poblemas arqueológicos, asumiendo que no constituyen un fin en sí mismas y que pueden tener un escaso valor si no se integran en el marco de modelos intepretativos generales. De esta forma, las técnicas de caracterización se alzan como un instrumento muy importante para emprender reconstrucciones más precisas acerca de las sociedades del pasado.

\section{BIBLIOGRAFÍA}

ABASCAL PALAZON, J., 1986: La cerámica pintada romana de tradición indigena en la Península lbéri$\mathrm{ca}$, Universidad de Alicante, Madrid.

ADAN-BAYEWITZ, D. y PERLMAN, I., 1985: «Local pottery provenience studies: a role for clay analysis», Archaeometry, 27 (2), 203-217.

AguAdo, J. 1986: «Cerámica hispanomusulmana de Toledo», Il Coloquio Internacional de Cerámica Medieval en el Mediterráneo Occidental, Toledo, 1981, Ministerio de Cultura, 127-134, Madrid.

AGUADO, J. et al., 1990: «El testar del puente de San Martín (Toledo)», Fours de potiers et "testares» médievaux en Mediterranée Occidentale. Méthodes et resultats, Publications de la Casa de Velázquez, Serie Archéologie XIII, 117-130, Madrid.

AgUAROD, C., 1991: Cerámica romana importada de cocina en la Tarraconense, Zaragoza.

ALARCÃo, A. y MAYET, F., eds., 1990: Ânforas lusitanas. Tipología, produçāo, comércio. Conimbriga 1988 , Coimbra.

ALIAGA, S. et al., 1991: «Tècniques experimentals per a l'estudi de la ceràmica», Limes, 1, 44-53. 
ANTON, G., 1973: Análisis por difracción de rayos $x$ de cerámicas ibéricas valencianas, SIP, núm. 45, Valencia.

ANTON, G. et al., 1972: «Contribución al estudio y clasificación de cerámicas ibéricas valencianas», BSECV, $11(1), 47-55$.

ARANEGUI, C. y ANTON, G., 1973: «Análisis por difracción de rayos x de cerámicas ibéricas. Cerámicas grises», XII CNA, 513-518, Zaragoza.

ARRIBAS, J. G. et al., 1987: «Estudio mineralógico comparativo de restos arqueológicos indígenas e importados de Tejada la Vieja (Escacena) y Huelva», $H A, 9,243-257$.

ARRIBAS, J. G. et al., 1988-89: «Datación absoluta por Termoluminiscencia y análisis mineralógico de materiales arqueológicos procedentes del yacimiento cueva de La Vaquera (Segovia)», Zephyrus, 41 $42,161-169$.

ARRIBAS, J. G. et al., 1991: «Caracterización mineralógica de cerámicas del yacimiento arqueológico de San Antonio (Vallecas, Madrid)», Arqueología, Paleontología y Etnografía, 2, 175-184.

AsPinall, A. y WARREN, S. E., eds.; 1983: Proceedings of the 22 $2^{\text {nd }}$ Symposium on archaeometry, University of Bradford, Bradford.

AYALA, M. ${ }^{a}$ M. y ORTIZ, R. J., 1987: «Análisis por difracción de rayos x de vasos de yeso hallados en la cueva de Amador. Cehegín, Murcia», APA, 3, 3-8.

AYALA, M. ${ }^{a}$ M. y ORTIZ, R. J., 1989: "Análisis por difracción de rayos x de vasos "de yeso" hallados en la comarca de Lorca. Murcia", XIX CNA, 309-322, Zaragoza.

BARBA, M. ${ }^{a}$ F., 1986: «Análisis mineralógico de 16 muestras de cerámica pintada de Segobriga (Saelices, Cuenca) y de una muestra de alfar de Los Pedregales en Clunia (Peñalba del Castro, Burgos)", en ABasCal Palazon, J., 1986: 289-304.

BARRIOS, J. et al., 1991 a: «Características estructurales y mineralógicas de cerámicas campaniformes procedentes de Monturque (Córdoba)», BSECV, 30 (3), 187-193.

BARRIOS, J. et al., 1991 b: «Materiales cerámicos de la campiña de Córdoba y su posible uso en la fabricación de vasos campaniformes», $X X X I C N C V, 87-88$, Madrid.

BAZZANA, A. et al., 1986: «Le problème de l'origine et de la diffusion des céramiques dites califales: recherche préliminaire", II Coloquio Internacional de Cerámica Medieval en el Mediterráneo Occidental, Toledo, 1981, Ministerio de Cultura, 33-38, Madrid.

BISHOP, R. L. et al., 1982: «Ceramic compositional analysis in archaeological perspective», en SCHIFFER, M. B., ed., 1982: 275-330.

BLÁZqueZ, J. M.a y VALIENTE, J., 1981: Cástulo III, EAE, núm. 117, Madrid.

BLÁZQUEZ, J. M.a et al., 1985: Cástulo V, EAE, núm. 140, Madrid.

BOMGARDNER, D. L., 1981: «Atomic absorption spectroscopy applications for ceramic analysis», en HUDGES, M. J., ed., 1981: 93-101.

BUKO, A., 1984: «Problems and research prospects in the determination of the provenance of pottery», $W A, 15$ (3), 348-365.

BUTZER, K. W., 1989: Arqueología. Una ecología del hombre: método y teoría para un enfoque contextual, Bellaterra, Barcelona.

CALDERON, T. et al., 1988: «Servicio de datación absoluta por Temoluminiscencia y analítica de cerámicas arqueológicas en la Universidad Autónoma de Madrid», CPA, 15, 385-397.

CAPEL, J., 1986: «Estudio mineralógico y geoquímico de sedimentos y cerámicas arqueológicas de algunos yacimientos de La Mancha», Oretum, 2, 55-153.

CAPEL, J. y DELGADO, R., 1978: «Aplicación de métodos ópticos al estudio de cerámicas arqueológicas», CPUG, 3, 343-356.

CAPEL, J. et al., 1979: «Métodos analíticos aplicados a cerámicas de la Edad del Bronce», CPUG, 4, 345-360.

CAPEL, J. et al., 1982: «Algunos aspectos del proceso de manufacturación de cerámicas neolíticas. Estudio del contenido de desgrasantes mediante lupa binocular», $C P U G, 7,73-111$.

CAPEL, J. et al., 1983: «Aplicación de métodos analíticos al estudio de cerámicas a la almagra», XIV CNA, 95-104, Zaragoza. 
CAPEL, J. et al., 1984: «Cerámicas con decoración a la almagra: identificación y caracterización de los términos almagra, aguada y engobe. Proceso decorativo", CPUG, 9, 97-114.

CAPEL. J. et al.. 1985: "High temperature reactions and use of Bronze Age pottery from La Mancha, central Spain", Miner. Petrogr. Acta (Clays and Clay Minerals), 29-A, 563-577.

CAPEL., J. et al., 1986 a: «La Sima de los Intentos: estudio óptico y mineralógico», CPUG, 11, 65-71.

CAPEL., J. et al., 1986 b: «Contribución de la geoquímica al estudio de la investigación prehistórica», Homenaje a Luis. Siret, 119-129, Sevilla.

CARR, C.. 1990: «Advances in ceramic radiography and analysis: applications and potentials», JAS, 17 (1), 13-34.

CASTELO, M. J. y RiNCON, J. M. a, 1986: «Arqueometría de dos cerámicas de una tumba ibérica de los Castellones de Ceal (Jaén)», AE, 9, 382-385.

CASTELO, M. J. y RINCON, J. M.`, 1987: «Microanálisis (MEB/EDX) de cerámicas ibéricas», Congreso Nacional de Microscopía Electrónica, Ávila 1986, 297-302.

CATLING, H. W., 1963: «Minoan and mycenaean pottery: composition and provenance», Archaeometry, $6,1-9$.

CATLING, H. W. y JONES, R. E., 1977: «A reinvestigation of the provenance of the inscribed stirrup jars found at Thebes", Archaeometry, 19, 137-146.

COURTOIS, L., 1976: Examen au microscope pétrographique des céramiques archéologiques, París.

CULBERT, T. P. y SCHWALBE, L. A., 1987: «X-ray fluorescence survey of Tikal ceramics», JAS, 14 (6), 635-657.

DARVILL, T. y TIMBY, J., 1982: «Textural analysis: a review of potentials and limitations», en Freestone, I. C. et al., eds., 1982: 73-87.

DE BRUIN, M. et al., 1976: «The use of trace element concentrations in the identification of objets", Archaeometry, 18 (1), 75-83.

DEMIANS, G. et al., 1986: «Recherches de laboratoire sur les ateliers medievaux espagnols», II Coloquio Internacional de Cerámica Medieval en el Mediterráneo Occidental, Toledo 1981, Ministerio de Cultura, 43-45, Madrid.

DíAZ BALDE, M." A., 1975: «Informe de laboratorio sobre muestras de cerámica procedentes de la cueva de "Los Cabezazos", Tegueste (Tenerife)», en Diego Cuscoy, L., 1975.

Diego CusCoY, L., 1975: «La cueva de "Los Cabezazos", en el barranco del agua de Dios (Tegueste, Tenerife)», $N A H, 4,289-335$.

ECHALLIER, J. C., 1981: «L'étude des mineraux argileux par diffraction des rayons x», Physio, 1, 43-58.

ECHALLIER, J. C., 1982: «La provenance des amphores massaliotes. Donnés nouvelles sur un problème d'histoire économique», DAM, 5, 139-144.

ECHALLIER, J. C., 1984: Eléments de technologie céramique et d'analyse des terres cuites archéologiques, DAM, Serie Méthodes et Techniques, núm. 3.

ECHALLIER, J. C. y JULLIEN, J., 1985: «Remarques sur des poteries iberiques du IVteme siècle av. J.-C. de la province d'Alicante (Espagne)», DT, 9, 113-117.

ERICSON, J. E. y EARLE, T. K. eds., 1982: Context for prehistoric exchange, Academic Press, Nueva York.

FERNÁNDEZ-POSSE, M.“ D. y SÁNCHEZ-PALENCIA, F. J., 1988: La Corona y el Castro de Corporales II, $E A E$, núm. 153, Madrid.

FRANKLIN, V. M. y VITALI, V., 1985: «The environmental stability of ancient ceramics», Archaeometry, $27(1), 3-15$.

FREESTONE, I. C., 1982: «Applications and potential of electron probe micro-analysis in technological and provenance investigations of ancient ceramics", Archaeometry, 24 (2), 99-116.

FREESTONE, I. C., et al., eds., 1982: Current researchs in ceramics: thin-section studies, BMOP, núm. 32 , Londres.

GALlART, M.^ D., 1977: «Las cerámicas de Sagunto: introducción a una metodología del estudio de las cerámicas de Sagunto y su relación con la geología de la zona", Saguntum, 12, 73-88. 
GALLART, M. D., 1980 a: «La tecnología de la cerámica neolítica valenciana. Metodología y resultados del estudio ceramológico por medio de microscopía binicular, difractometría de rayos x y microscopía electrónica», Saguntum, 15, 57-91.

GALlART, M.` D., 1980 b: «La tecnología cerámica», en Marti Oliver, B. et al., 1980: 165-173.

GALlART, M. D. y LÓPEZ, F., 1988 a: «Mineralogía de cerámicas de la Edad del Bronce de la Cuenca del Moro (Olvena, Huesca)", Bolskan, 5, 27-38.

GALlART, M.` D. y LÓPEZ, F., 1988 b: «Análisis mineralógico de las cerámicas neolíticas de la Cueva de Chaves (Casbas, Huesca)», Bolskan, 5, 5-26.

GALVÁN, J., 1980-81: «Aplicación de las técnicas de microscopía electrónica y difracción de rayos x al estudio de la cerámica de "El Perchel" en Arcos del Jalón (Soria)", CPA, 7-8, 161-168.

GALVÁN, J. y GALVÁN, V., 1987: «Estudio mineralógico de cerámicas procedentes de "El Llanete de los Moros" (Montoro, Córdoba)», en Martín de la Cruz, J. C., 1987: 270-278.

GALVÁN, J. y GALVÁN, V., 1988: «Estudio mineralógico de muestras de cerámica y arcilla procedentes

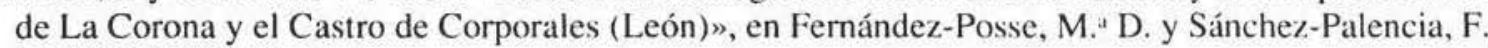
J., 1988: 249-250.

GALVÁN, J. et al., 1973: «Estudio mineralógico de cerámica de la Edad del Bronce, de la cueva de La Vaquera (Segovia)», XII CNA, 241-250, Zaragoza.

GALVÁN, J. et al., 1974: «Análisis por difracción de rayos x y microscopía electrónica de la cerámica de Esmeraldas, Ecuador», XLI CIA, México.

GALVÁN, J. et al., 1989: «Estudio mineralógico de cerámicas procedentes del yacimiento arqueológico de La Tolita (Ecuador)», XLVI CIA, BAR, Int. Ser., núm. 503, Oxford.

GALVÁN, V., 1991: «Estudio mineralógico de la cerámica grafitada», Arqueología, Paleontología y Etnografía, 2, 1985-1986.

GANCEDO, J. R. et al., 1985: «Mössbauer spectroscopic, chemical and mineralogical characterization of iberian pottery», Archaeometry, 27 (1), 75-82.

GARCÍA HERAS, M., 1992: «Arqueología y Ciencia. La caracterización de cerámicas arqueológicas en España», Arqrítica, 3, 3-5.

GARCÍA RAMOS, G. et al., 1974: «Materias primas y técnicas empleadas en artesanía popular de la tierra cocida en Extremadura», EG, 30, 407-421.

GERRARD, C. M. y GUTIÉRREZ, A., 1988: «El análisis de secciones delgadas y la caracterización macroscópica de algunas cerámicas medievales encontradas en Aragón», BMZ, 7, 133-158.

GERRARD, C. M. y GUTIÉRREZ, A., 1991: «The thin-section analysis and macroscopic characterization of some medieval and post-medieval pottery from northern Spain», en Middleton, A. P. y Freestone, I. C., eds., 1991: 113-135.

GONZÁlez, A. y PINA, J. A., 1983: «Análisis de las pastas cerámicas de vasos hechos a torno de la fase orientalizante de Peña Negra (675-550/35 A. C.)», Lucentum, 2, 115-145.

GONZÁlEZ, M.`C. et al., 1983: «Cerro Macareno (Sevilla) pottery: the nature and provenance of amphoras and other earthenware posts from VIII to III centuries B. C.», en Aspinall, A. y Warren, S. E., eds., 1983: 388-403.

GoNZÁLEZ, M. ${ }^{a}$ C. et al., 1985 a: «Productos de alfarería de Cerro Macareno (Sevilla). Naturaleza y procedencia de las ánforas y otros objetos cerámicos. Siglos VIII al III a. J.», NAH, 21, 157-174.

GoNZÁLEZ, M. ${ }^{a}$ C. et al., 1985 b: «Materias primas y datos tecnológicos de piezas cerámicas antiguas del yacimiento arqueológico de Cerro Macareno (Sevilla)», BSECV, 24 (3), 173-186 y 24 (4), 219 232 .

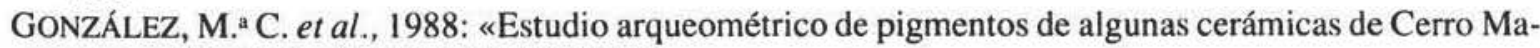
careno (Sevilla)», BSECV, 27 (2), 73-80.

GONZÁlEZ PEÑA, J. M., 1974: «Relación entre las características físicas del componente arcilloso y el comportamiento de las pastas cerámicas», EG, 30, 399-406.

GOSDEN, C. H., 1987: «The production and exchange of La Tène A. wheel-turned pottery in Bohemia», $A R, 39$ (3), 290-316. 
GRACIA, M.. 1980: Estudio de cerámicas de interés arqueológico por espectroscopía Mösshauer. Fundación Juan March, Madrid.

GUINEA, M. y J. GAL.VÁN, 1976: «Relaciones comerciales de Esmeraldas como resultado del análisis de las cerámicas por difracción de rayos $\mathrm{x}$ y microscopía electrónica», XLII CIA. París.

HARBOTTL.E. G.. 1982: "Chemical characterization in archaeology», en Ericson, J. E. y Earle, T. K., eds., 1982: 13-51.

HARRISON, R. J. et al., 1987: «Moncín: poblado prehistórico de la Edad del Bronce (1)», NAH, 29, 7-102.

HUGHES, M. J., ed., 1981: Scientific studies in ancient ceramics, BMOP. núm. 19, Londres.

HUGHES, M. J. et al., eds., 1991: Neutron activation and plasma emission spectrometric analysis in archaeology. Techniques and applications, BMOP, núm. 82, Londres.

ISIDRO, A. y NAVARRO, F., 1990: "Análisis por difracción de rayos $\mathrm{x}$ de cerámicas prehistóricas de la isla de El Hierro (Islas Canarias)», en Rincón, J. M. a, ed., 1990: 271-276.

JORNET, A., 1984 a: «Arqueometría: estudios sobre cerámica arqueológica», Revista de Arqueología, 35 , $18-27$.

JORNET, A., 1984 b: «La cerámica en la arqueometría», BMAN, 2, 77-84.

Juan TOVAR, L. C., 1992: «Alfares y hornos de la antigüedad en la Península Ibérica: algunas observaciones en torno a su estudio", Tecnología de la cocción cerámica desde la Antigüedad a nuestros días. Asociación de ceramología del centro Agost, 65-85, Alicante.

JuAn TOVAR, L. C. y BeRmúdeZ, A., 1991: «Talleres cerámicos en la Prehistoria y Protohistoria de la Península Ibérica: introducción a su estudio», Rivista di Archeologia, 15, 116-124.

KAMILLI, D. C. y LAMBERG-KARLOVSKY, C. C., 1979: «Petrographic and electron microprobe analysis of ceramics from Tepe Yahya, Iran», Archaeometry, 21 (1), 47-59.

KINGERY, W. D., 1974: «A notes on the differential thermal analysis of archaeological ceramics», $A r$ chaeometry, 16 (1), 109-112.

LINARES, J. et al., 1983: «La arcilla como material cerámico. Características y comportamiento», CPUG. $8,479-490$.

Maniatis, Y., ed., 1989: Archaeometry. Proceedings of the $25^{\text {th }}$ International Symposium, Elsevier Science Publishers, Amsterdam.

MANIATIS, Y., et al., 1982: «The investigation of ancient ceramic technologies by Mössbauer spectroscopy", en Olin, J. S. y Franklin, A. O., eds., 1982: 97-108.

MARTI OLIVER, B. et al., 1980: Cova de l'Or (Beniarrés, Alicante), SIP, núm. 65, Valencia.

MARTín dE LA CRUZ, J. C., 1987: El Llanete de los Moros. Montoro, Córdoba, EAE, núm. 151, Madrid.

MARTíN PATINO, M." T., 1985: «Caracterización química y mineralógica del alfar de Badajoz», en Valdés Fernández, F., 1985: 337-345.

MARTÍN SOCAS, D. et al., 1985: «Composición mineralógica y evaluación de las temperaturas de cocción de la cerámica de Campos (Cuevas de Almanzora, Almería). Estudio preliminar», CPUG, 10, 131-185.

MARTíN SOCAS, D. et al. 1989: «Mineralogical composition and evaluation of firing temperatures of the Purchena pottery (Almería, Spain)», en MANIATIS, Y. ed., 1989.

MAYET, F., 1984: Les cerámiques sigillées hispaniques. Contribution à l'histoire économique de la Péninsule Ibérique sous l'Empire Romain, tomo I, CNRS, París.

MIDDLETON, A. P. y FREESTONE, I. C., eds., 1991: Recent Developments in Ceramic Petrology, BMOP, núm. 81, Londres.

MIDDLETON, A. P. et al., 1985: «Textural analysis of ceramic thin sections: evaluation of grain sampling procedures", Archaeometry, 27 (1), 64-74.

MILLÁN, A. et al., 1991: «Caracterización mineralógica de cerámicas campaniformes: yacimiento Preresa (Madrid)", EPAM, 7, 57-70.

MINGARRO, F. y LÓPEZ, M. ${ }^{a}$ C., 1982: «Petrología arqueológica de Pachacanac, Perú: materiales de construcción y cerámicas", REAM, 12, 157-173.

MUÑOZ, I. et al., 1991: «Estudio arqueométrico de cerámicas de Salobreña (Granada)», XXXI CNCV, 8990, Madrid. 
NAVARRETE, M.`S. y CAPEL, J., 1980: «Algunas consideraciones sobre la cerámica a la almagra del Neolítico andaluz», CPUG, 5, 15-35.

NAVARRETE, M. 'S. et al., 1991: Cerámicas neolíticas de la privincia de Granada. Materias primas y técnicas de manufacturación. Universidad de Granada, Granada.

NiCHOLSON, P. T., 1989: Iron Age pottery production in the Hunsrück-Eifel-Kultur of Germany. BAR, Int. Ser., núm. 501, Oxford.

OLIN, J. S. y FRANKLIN, A. O., eds., 1982: Archaeological ceramics, Smithsonian Institution, Washington.

PADILLA, J. I., 1980: «Primeros análisis químicos y espectroscópicos de la cerámica gris», La céramique médiévale en Mediterranée Occidentale, Valhonne 1978, CNRS. Colloques Internationaux, núm. 584, 397-402, París.

PEACOCK, D. P. S., 1967: «The heavy mineral analysis of pottery: a preliminary report», Archaeometry, 10, 97-100.

PEACOCK, D. P. S., 1970: «The scientific analysis of ancient ceramics: a review», WA, I (3), 375-389.

PEACOCK, D. P. S., 1974: "Amphorae and the baetican fish industry», A.J, 54 (2), 232, 243.

PEACOCK, D. P. S., ed., 1977: Pottery and early commerce. Characterization and trade in roman and later ceramics, Academic Press, Londres.

PELÁEZ, M. ${ }^{a}$ N., 1982-83: «Puesta a punto de algunas técnicas físico-químicas para el estudio de cerámicas arqueológicas», $C P A, 9-10,151-210$.

PICON, M., 1973: «Recherches de laboratoire sur la céramique antique», Revue Archéologique, 1, 119. 132.

PICON, M., 1984: «Recherches sur les compositions des sigillées hispaniques. Techniques de fabrication et groupes de production», en MAYET, F., 1984: 303-317.

PICON, M., 1987: «La fixation du baryum et du strontium par les céramiques», RdA, 11, 41-47.

PICON, M., 1991: «L'analyse par activation neutronique est-elle la meilleure méthode que l'on puisse employer pour determiner l'origine des céramiques?», RdA, 15, 95-101.

PICON, M. y NAVARRO, J., 1986: «La loza dorada de la province de Murcie: étude en laboratoire», La ceramica medievale nel Mediterraneo Occidentale. III Congresso Internazionale, Siena-Florencia 1984, Edizioni all'Insegna del Giglio, 144-146, Florencia.

PINTO, A. V. y CARDOSO, J. L., 1990: «Estudos sobre pastas de ânforas de fornos do vale do Tejo e do vale do Sado: análises macro e microscópicas», en Alarcão, A. y Mayet, F., eds., 1990: 267-271.

PRADELL, T. et al., 1991: «Cerámica gris medieval catalana: caracterización y tecnología de producción», A cerâmica medieval no Mediterrâneo Ocidental. IV Congresso Internacional, Lisboa 1987. Campo Arqueológico de Mértola, 601-610, Mértola.

RENFREW, C., 1977: «Introduction: production and exchange in early state societies, the evidence of pottery», en Peacock, D. P. S., ed., 1977: 1-20.

RENFREW, C. y P. BAHN, 1991: Archaeology, Theories, methods and practice, Thames \& Hudson, Londres.

RICE, P. M., 1987: Pottery analysis: a sourcebook, Chicago University Press, Chicago.

RinCón, J. M.a 1981 a: «Estudio de la composición de los colorantes superficiales de dos cerámicas del poblado de la Muela de Cástulo (Linares, Jaén)», en Blázquez, J. M. a y Valiente, J., 1981: 237-242.

RINCóN, J. M. 1981 b: «Estudio comparativo de los colorantes superficiales rojos de varias piezas cerámicas del poblado de la Muela de Cástulo (Linares, Jaén)», en Blázquez, J. M.a y Valiente, J., 1981: 243-249.

RINCÓN, J. M." 1983: «Aplicación de la micro-sonda raman al estudio de cerámicas prehistóricas», TP. $40,273-282$.

RINCÓN, J. M.a 1985 a: «Estudio mineralógico de piezas cerámicas de la Edad del Bronce del poblado de la Muela de Cástulo», en Blázquez, J. M." et al., 1985: 319-328.

RINCóN, J. M.* 1985 b: «Análisis mineralógico de piezas de cerámica común e ibérica de Cástulo», en Blázquez, J. M.a et al., 1985: 329-337. 
RINCÓN. J. M." 1985 c: "Mineralogía de las cerámicas de la Edad del Bronce del yacimiento del Cerro de San Pedro (Huelva)", en Blázquez, J. M.`et al., 1985: 339-344.

RINCÓN, J. M." 1985 d: "Composición mineralógica y microestructura de cerámicas de "Terra Sigillata" de la Península Ibérica», en Blázquez. J. M.“et al., 1985: 345-362.

RINCÓN, J. M.* 1986: "Caracterización arqueométrica de un fragmento de cerámica pintada procedente del cerro de la Virgen de la Muela (Driebes, Guadalajara)", en Abascal Palazón, J., 1986: 305-312.

RinCón. J. M." ed., 1990: Ciencia y Tecnología de los materiales cerámicos y vítreos. España'89. Faenza Editrace Ibérica, S. L., Castellón.

RINCÓN, J. M." y M. J. ALONSO, 1990: «Estudio arqueométrico de materiales cerámicos campaniformes de la provincia de Zamora», $X X X C N C V$ (inédito).

RINCÓN, J. M. y VALLE, F. J., 1983: «Estudio mineralógico por DRX de diferentes piezas cerámicas prehistóricas de "fondos de cabaña" de Getafe (Madrid)", EPAM, 2, 255-263.

RINCÓN, J. M.`et al., 1990: «Estudio macro y microanalítico de cerámicas indígenas de la isla de El Hierro (Islas Canarias)», en Rincón, J. M.a 1990: 265-270.

RIU, M., 1986: «Estat actual de les recerques sobre les céramiques grises i la terrisa popular de la Catalunya medieval», La ceramica medievale nel Mediterraneo Occidentale. III Congresso Internazionale, Siena-Florencia 1984, Edizioni all'Insegna del Giglio, 219-225, Florencia.

SAYRE, E. V. y DODSON, R. W., 1957: «Neutron activation study of mediterranean potsherds», A.JA, 61, $35-41$.

SCHIFFER, M. B., ed., 1982: Adrances in archaeological method and theory, 5, Academic Press, Nueva York.

SHOTTON, F. W. y HENDRY, G. L., 1979: «The developing field of petrology in archaeology», JAS, 6 (1), 75-84.

SLATER, E. A. y TATE, J. O., eds., 1988: Science and Archaeology, BAR, Brit. Ser., núm. 196, Oxford.

STERN, W. B. y DESCOEUDRES, J. P., 1977: «X-ray fluorescence analysis of archaic greek pottery», Archaeometry, $19(1), 73-86$.

TAVARES, A., 1984: «Caractérisation de quelques types de fabrication de sigillées hispaniques», en Mayet, F., 1984: 299-302.

TAVARES, A., 1990: «Composição mineralógica de ânforas do vale do Sado», en Alarcão, A. y Mayet, F., eds., 1990: 259-266.

TITE, M. S., 1969: «Determination of the firing temperature of ancient ceramics», Archaeometry, 11, 131143.

TITE, M. S. y MANIATIS, Y., 1975: «Examination of ancient pottery using the scanning electron microscope», Nature, 257, 122-123.

TITE, M. S. et al., 1982: «The use of scanning electron miscroscopy in the technological examination of ancient ceramics», en Olin, J. S. y Franklin, A. O., eds., 1982: 109-120.

TUBB, A. et al., 1980: «The analysis of romano-british pottery by atomic absorption spectrophotometry», Archaeometry, 22 (2), 153-171.

URTEAGA, M. ${ }^{a}$ M., 1991: «La cerámica roja de Valladolid», A cerâmica medieval no Mediterrâneo Ocidental. IV Congresso Internacional, Lisboa 1987, Campo Arqueológico de Mértola, 263-272, Mértola.

VALDÉS FERNÁNDEZ, F., 1985: La alcazaba de Badajoz, EAE, núm. 144, Madrid.

VENDRELL-SAZ, M., et al., 1989: «Étude de laboratoire des productions de Saint-Gilles-du-Gard», AMM, 7, 105-107.

VENDRELL-SAZ, M. et al., 1991: «Proto-campanian and A-campanian ceramics: characterization of the differences between the black coatings", Archaeometry, 33 (1), 109-117.

VILA, A. y ESTÉVEZ, J., 1989: «"Sola ante el peligro": la arqueología ante las ciencias auxiliares», AEspA, $62,272-278$.

WEYMOUTH, J. W., 1973: «X-ray diffraction analysis of prehistoric pottery», AmA, 38, 339-344.

WILLIAMS, D. F., 1977: «The romano-british black-burnished industry: an essay on characterization by heavy mineral analysis», en Peacock, D. P. S., ed., 1977: 163-220. 
WILSON, A. L., 1978: «Elemental analysis of pottery in the study of its provenance: a review», JAS, 5 (3), 219-236.

\section{ABREVIATURAS UTILIZADAS}

AE: Arqueología Espacial.

AEspA: Archivo Español de Arqueología. AJ: Antiquaries Journal.

AJA: American Journal of Archaeology.

AmA: American Antiquity.

AMM: Archéologie du Midi Médiéval.

APA: Anales de Prehistoria y Arqueología.

AR: Archeologické Rozhledy.

BAR: British Archaeological Report.

BMAN: Boletín del Museo Arqueológico Nacional.

BMOP: British Museum Occasional Paper.

BMZ: Boletín del Museo de Zaragoza.

BSECV: Boletín de la Sociedad Española de Cerámica y Vidrio.

CIA: Congreso Internacional de Americanistas.

CNA: Congreso Nacional de Arqueología.

CNCV: Congreso Nacional de Cerámica y Vidrio.

CNRS: Centre National Recherche Scientifique.
CPA: Cuadernos de Prehistoria y Arqueología.

CPUG: Cuadernos de Prehistoria de la Universidad de Granada.

DAM: Documents d'Archéologie Méridionale.

DT: Documents et Travaux.

EAE: Excavaciones Arqueológicas en España.

EG: Estudios Geológicos.

EPAM: Estudios de Prehistoria y Arqueología Madrileña.

HA: Huelva Arqueológica.

JAS: Journal of Archaeological Science.

NAH: Noticiario Arqueológico Hispánico.

RdA: Revue d'Archéométrie.

REAM: Revista Española de Antropología Americana.

SIP: Servicio de Investigación Prehistórica.

TP: Trabajos de Prehistoria.

WA: World Archaeology. 